\title{
LOS JÓVENES ANTE LOS DERECHOS HUMANOS Y LA DEMOCRACIA (A propósito de una encuesta realizada en la Comunidad Valenciana)
}

GRUPO DE INVESTIGACIÓN I+D

Departamento de Derecho Constitucional

Facultad de Derecho de Valencia 


\section{SUMARIO}

Presentación. El grupo de investigación. l. Causas y propósitos de este estuDio. II. La encuesta realizada, obtención de datos y metodología. A) Planteamiento de la encuesta. B) Breve comentario de la metodología empleada. C) Sistematización del análisis de los resultados en cuatro grandes áreas. III. EL DESCONOCIMIENTO DE ELEMENTOS BÁSICOS DE UNA CULTURA DEMOCRÁtICA. A) Grado de acercamiento a los conceptos básicos. B) Percepción del nexo derechos humanos-democracia-Constitución. C) Conocimiento de instituciones y personalidades. IV. SENSIBILIZACIÓN DEL ALUMNADO EN TORNO AL RESPETO REAL DE ESTOS DERECHOS. V. AsPECTOS DE MADUREZ - INQUIETUd POLITICA. A) Sobre el actual sistema democrático y el sentimiento de ciudadanía. B) Pena de muerte y culpabilidad de la persona. C) Interdicción de la xenofobia en las aulas, la apuesta por la tolerancia. VI. OPORTUNIDAD DE UNA ENSEÑANZA DE LOS DERECHOS HUMANOS. VII. A MODO DE RECAPITULACIÓN. 


\title{
LOS JÓVENES ANTE LOS DERECHOS HUMANOS Y LA DEMOCRACIA (A propósito de una encuesta realizada en la Comunidad Valenciana)
}

\author{
POR \\ GRUPO DE INVESTIGACIÓN I+D \\ Departamento de Derecho Constitucional \\ Facultad de Derecho de Valencia
}

\section{PRESENTACIÓN}

Tenemos el gusto de dirigirnos a usted sabedores de que el estudio que le presentamos será, sin duda, de su interés. El objeto del mismo es tanto la educación y la enseñanza como el avance en la consolidación democrática. Dada su especial relación con estos ámbitos tenemos a bien remitirle el presente. Los autores del mismo constituimos un pequeño grupo de investigación del Departamento de Derecho Constitucional de la Facultad de Derecho de Valencia. Dos realidades se unen en nuestra profesión, de un lado la enseñanza, de otro lado la Constitución y el Derecho, a los que dedicamos el estudio y la propia dedicación docente.

Es así, que hemos llevado al campo de investigación estas dos realidades, educación y Constitución, y ciertamente creemos que las posibilidades que se abren son del máximo interés para nuestra socie- 
dad. No somos pocos quienes, desde todos los estamentos, perseguimos la efectividad de los derechos humanos, quienes participamos en la continua tarea de la consolidación democrática. $Y$ no siempre se tiene en cuenta que hoy día contamos con un instrumento sin igual para el avance en esta tarea, el sistema educativo.

El presente trabajo pretende especialmente dar a conocer los resultados de unas encuestas entre el alumnado de BUP y COU, realizadas en la Comunidad Valenciana. No dudamos del atractivo de lo que ahora le presentamos, uno más de los trabajos que en esta línea hemos realizado. Todo ello conscientes de que nos une con la institución que dirige un noble interés común.

\section{EL GRUPO DE INVESTIGACIÓN}

El estudio que tiene en sus manos es fruto del trabajo del grupo investigador formado por:

- Remedio Sánchez Ferriz, catedrática de Derecho Constitucional de la Universidad de Valencia. Especialista en el campo de las libertades públicas $y$ especialmente en las informativas, entre sus obras más destacadas se encuentran "El derecho a la información" (1974), "La Constitución de 1876 y el sistema político de la Restauración" (1984), "Introducción al Estado Constitucional» (1993) y "Estudio sobre las libertades" (1989 y 1995). Con Luis Jimena Quesada ha escrito recientemente "La enseñanza de los derechos humanos" (1995).

- Luis Jimena Quesada, Doctor en Derecho (primer doctorado europeo en la Facultad de Derecho de Valencia), ejerce en ésta como profesor ayudante de Derecho Constitucional desde 1992. Sus principales tareas las ha desempeñado en el campo de los derechos humanos, y principalmente en el ámbito de la enseñanza. Cuenta con numerosas publicaciones en la materia, destacando su libro del que es coautor con Remedio Sánchez sobre "La enseñanza de los derechos humanos". Ha sido Director de Estudios (1993) y Profesor (1994) del Instituto Internacional de Derechos Humanos.

- Lorenzo Cotino Hueso, Licenciado en Derecho por la Universidad de Valencia y desde 1996, becario de investigación de la Generalitat Valenciana, especializándose en materia de libertades públicas, $y$ más concretamente en el tratamiento constitucional del sistema educativo. Obtuvo el Premio de Investigación jurídica de la Facultad de Derecho de Valencia por su trabajo titulado "La libertad de cátedra" (1995). 
Respecto de la materia que ahora le presentamos, este grupo ya ha contado con el apoyo de la Universidad de Valencia, habiéndose consolidado, desde 1996, en el Proyecto de Investigación y Desarrollo titulado "Educación en derechos, consolidación de la democracia", financiado por la Generalitat Valenciana.

Son varias las publicaciones realizadas por los miembros de este grupo investigador, aunque destaca sobremanera el libro "La enseñanza de los derechos humanosı, Ariel, Barcelona, 1995. En él Remedio Sánchez y Luis Jimena realizan el primer análisis juridico serio sobre la cuestión. Se tratan en esta obra tanto los antecedentes históricos, la jurisprudencia y la regulación constitucional e internacional. Asimismo se dedica una buena parte del estudio al análisis de la situación de la cuestión en el marco comparado.

Es nuestro propósito no abandonar el plano de la investigación que hasta ahora hemos ido desarrollando ni, por supuesto, el enfoque constitucional de la misma pero estamos convencidos de que el principal efecto que esta tarea pudiera surtir es el de su difusión a la mayor escala posible y ello sólo será viable creando una mínima estructura o puente de conexión entre nuestra inquietud y nuestra tarea investigadora universitaria y los agentes sociales de los que realmente, y según nuestro planteamiento, depende la consolidación democrática: los docentes, desde luego, en todos sus niveles pero no sólo ellos; también otras escalas y cuerpos de funcionarios cuyo papel no es menos decisivo en esta tarea de respeto y difusión de los derechos y libertades, aparte comportan un deber que muchos de ellos desconocen.

Nos proponemos, pues, solicitar de algunas instituciones el apoyo material y la cobertura institucional necesaria para llevar a cabo cursos y seminarios abiertos al profesorado, funcionarios y estudiantes de último año o de doctorado que se hallen realmente interesados en el tema.

\section{CAUSAS Y PROPÓSITOS DE ESTE ESTUDIO}

La importancia de la consolidación del Estado democrático y de la efectividad de los derechos humanos constituye un argumento válido para dotar de interés a cualquier trabajo de investigación. Quienes hemos realizado el presente estudio ${ }^{1}$ estamos convencidos

\footnotetext{
1 El presente estudio se incluye en el conjunto de trabajos realizados en el marco del Proyecto de Investigación y Desarrollo financiado por la Generalitat Valenciana, al cual están adscritos los autores del mismo.
} 
de que la enseñanza y la educación son medios insustituibles para alcanzar aquellos propósitos ${ }^{2}$. Hablar de la enseñanza de los derechos es, por más que hoy siga pareciendo extraño a muchos juristas, hablar de su implantación real y efectiva y, consiguientemente, sentar las bases de una democracia avanzada, tal como reza nuestro Preámbulo constitucional. En virtud de la relevancia de la educación en democracia y en derechos humanos, hemos tenido a bien llevar a cabo un seguimiento de la realidad de ésta en diversos centros educativos.

El art. 27.2. de nuestra Constitución dispone que "La educación tendrá por objeto el pleno desarrollo de la personalidad humana en el respeto a los principios democráticos de convivencia y a los derechos y libertades fundamentales». Este precepto, configurador del sistema educativo diseñado en la Constitución de 1978, parece considerarse en ocasiones vacío de contenido. Apenas publicada nuestra Norma Fundamental, el legislador se ocupó del tema con la Ley 19/1979 de 3 de octubre por la que se reguló el conocimiento del ordenamiento constitucional. Su objetivo no era otro que acercar a los jóvenes al texto fundamental como instrumento decisivo para la consolidación de la democracia. Más que imponer la adquisición de unos datos o conocimientos mínimos, se intentaba fomentar la motivación del alumnado hacia estas cuestiones.

La primera ocasión en que se trató de conocer el nivel de cumplimiento de esta normativa en la Comunidad Valenciana fue en el año 1984, momento en que debía estar ya aplicándose durante cuatro cursos académicos $y$, aunque con muchas dificultades, en buen número de Centros de Segunda Enseñanza se apreciaba el interés por parte del profesorado de integrarse en la filosofía de la citada norma. Con posterioridad, tal entusiasmo inicial parece haber decaido año tras año, al no verse acompañado de medios suficientes para verse fomentado (horario propio para la materia, libros o materiales -que sí existían, aunque en reducido número, con firmas autorizadas-l, ni con actividades tendentes a fomentar y mantener el propio interés del profesorado por una materia que, en principio, les es ajena. Tras casi dos décadas de régimen democrático, resulta nuevamente un sano ejercicio investigar hasta qué punto ha sido efectivo este mandato constitucional. Es interesante volver a preguntarse si se ha inculcado el respeto a los de-

2 Ver, por todos, R. SÁNCHEZ y L. JIMENA, La enseñanza de los derechos humanos. Barcelona. Ariel, 1995. 
rechos humanos y a los principios democráticos por medio de la educación. Para ello, realizamos una serie de encuestas cuyos resultados desarrollamos en las siguientes páginas.

\section{LA ENCUESTA REALIZADA, OBTENCIÓN DE DATOS Y METODOLOGÍA}

Durante el año 1994 se realizaron más de 800 encuestas en distintos centros de enseñanza media de la Comunidad Valenciana. EI análisis de las mismas que aquí se proyecta se refiere a un total de 587 encuestas de otros tantos alumnos, pertenecientes a nueve Institutos de Bachillerato y a la Facultad de Derecho de Valencia. Sobre este conjunto se ha aplicado una metodología homogénea, susceptible de ser tratada estadísticamente. La exploración consistía en 23 preguntas, que en su mayor parte podían ser respondidas con un sucinto comentario. A continuación se detallan los elementos del estudio así como la consecuente metodologia empleada.

\section{A) Planteamiento de la encuesta}

\section{Elementos subjetivos}

Resulta imprescindible apuntar a una referencia a los sujetos consultados, asi como a los centros a los que pertenecian. El grupo encuestado estaba formado por alumnos de los cursos de B.U.P. y C.O.U., de edad aproximada entre 17 y 19 años. Este colectivo representa una primera generación postfranquista, jóvenes que han desarrollado su vida íntegramente en un sistema democrático. Estos jóvenes, actualmente, ya han tenido la oportunidad de votar. Por otro lado, y para operar una comparación, se distribuyó la misma encuesta a alumnos de primer curso de la Licenciatura de Derecho, alumnos que, al momento de cumplimentarlas, no habian tenido aún la ocasión de recibir ninguna clase. Este colectivo sondeado, teóricamente mostraba un especifico interés por la rama de Derecho que habían decidido cursar; no obstante, su formación era la del bachillerato.

Los institutos explorados fueron seleccionados como representativos del conjunto. De entre los nueve que aquí se analizan, los hay públicos, privados, religiosos y laicos. Del mismo modo, se han inclui- 
do centros emplazados en ámbitos socioeconómicos más o menos favorecidos, más o menos marginales ${ }^{3}$.

\section{Las cuestiones planteadas}

Como se aludió anteriormente, la finalidad de esta investigación no obedecia directamente a la elaboración de un completo y técnico estudio sociológico; se pretendía más bien captar el estado de la educación y enseñanza de los derechos humanos y los principios democráticos. Bien conseguido este primer propósito con el análisis de las encuestas, se ha revelado útil cuantificarlo en buena medida. Obviamente, la concreción objetiva de estos resultados ha dependido de la naturaleza de las cuestiones planteadas.

En algún caso concreto la modalidad de respuesta solamente ofrecía la posibilidad de elección entre opciones prefijadas; de este modo la objetivización de las contestaciones era indudable ${ }^{4}$. En otros casos, los más, el abanico de las respuestas posibles era fácilmente objetivable, si bien, al ser preguntas de desarrollo se permitía que los alumnos añadieran valoraciones, o que se extendiesen en mayor o menor grado en sus consideraciones ${ }^{5}$. Estas valoraciones no siempre se han podido plasmar en una traducción porcentual. Surgía así, en el análisis de las encuestas un elemento añadido que, por subjetivo, era difícilmente cuantificable, aunque ha sido tenido en cuenta. Este elemento subjetivo, presente en la mayoría de las contestaciones, unas veces marcaba el nivel de conocimiento de los encuestados, otras veces manifestaba su talante político, sus inquietudes personales, etc. Finalmente, existen preguntas en las que directamente se pretendia conocer elementos no objetiva-

3 A continuación se detallan los nueve centros seleccionados; se acompaña una breve referencia a su carácter público o privado, y de entre éstos, su carácter religioso o laico:

Por un lado citar los siguientes institutos públicos: I.B. El Clot, I.B. Ontinyent, I.B. Picassent, I.B. Jesús Ballester (de Valencia), el I.B. Almassora y el I.B. Segorbe (de Castellón). También fue encuestado el I.B. Martín Sorolla II, de Valencia, centro privado laico. Por último, se encuentran analizados los institutos privados religiosos Carmelitas (de Castellón) y Salesianos (de Valencia).

4 Por ejemplo, en la pregunta $n .^{\circ} 5$ se daban a elegir de dos posibilidades con las que identificar una democracia. Del mismo modo en las preguntas 10,16 y 22 .

5 Por ejemplo, preguntas como «¿Crees que vives en una democracia? ¿Por qué?» o del estilo de “¿Deben tener los mismos derechos los españoles que los extranjeros? ¿Por qué?». 
bles $^{6}$. Todo este conjunto no directamente cuantificable se proyecta en el presente análisis.

\section{LISTADO DE PREGUNTAS}

1. ¿Qué son los derechos humanos? Enumera una lista de los que conozcas.

2. ¿Sabes si hay alguna relación entre la Constitución española y los derechos humanos?

3. ¿Crees que existe alguna relación entre democracia y derechos humanos?

4. ¿Crees que vives en una democracia? ¿Por qué?

5. ¿A cuál de estas dos ideas crees que se vincula más una democracia?

- al respeto de minorías y de toda persona.

- al respeto al poder de las mayorias elegidas.

6. ¿Te sientes ciudadano? ¿Qué significa para tí?

7. ¿Deben tener los mismos derechos los españoles que los extranjeros? ¿Por qué?

8. Señala, de entre estas instituciones y organizaciones aquéllas que conozcas y separas para qué sirven:

- Parlamento.

- Defensor del Pueblo.

- Fiscal.

- Organización de las Naciones Unidas (ONU).

- Consejo de Europa.

- Amnistía Internacional.

9. ¿Sabes lo que es un Estado de Derecho?

10. ¿Consideras culpable a una persona, antes del juicio, sin esperar sentencia?

- cuando tú mismo eres testigo del hecho presuntamente delictivo.

${ }^{6} \quad$ Así pues, se incluyen cuestiones abiertas, como las relativas al significado de ciudadanía, o sobre posibles soluciones en contra de las agresiones de los derechos humanos, etc. 
- cuando lo lees en la prensa.

- cuando lo ves en TV.

- nunca antes de que el juez se pronuncie.

11. ¿Crees que hoy en día se respetan los derechos humanos? En caso negativo, te atreverías a dar alguna solución?

12. ¿Cuántas instituciones actuales, dentro y fuera de España, puedes recordar de vulneración de los derechos humanos?

13. Conoces y sabes qué hacen/hicieron:

- Martin Luther King.

- Rigoberta Menchu.

- Teresa de Calcuta.

- Gandhi.

14. ¿Crees que es importante la enseñanza de los derechos humanos? ¿Por qué?

15. ¿Cómo piensas que funcionaría mejor nuestra sociedad?, si los derechos humanos fueran conocidos por:

- especialistas.

- todas las personas.

16. ¿Estás a favor de la pena de muerte?

- en ningún caso.

- en casos como terrorismo, violación o crímenes muy graves.

- para delincuentes en general.

- otros (indica el caso).

17. ¿Sabes lo que la Constitución dice sobre la pena de muerte?

18. ¿Te casaría con una persona de otra raza?

19. ¿Convivirías con un español de raza gitana?

20. ¿Crees que es posible una amistad sincera entre quien se considere fascista y quien se considera comunista?

21. ¿Juzgarías del mismo modo la injusticia cometida por un amigo o persona perteneciente a tu grupo que la cometida por un extraño?

22. En tu entorno se trata de forma igual a:

- homosexuales.

- disminuidos físicos.

- disminuidos mentales.

- personas obesas, feas, diferentes en el vestir...

- extranjeros.

23. Indica si quieres, alguna reflexión personal más. 


\section{B) Breve comentario de la metodología empleada}

Desde un primer momento hemos entendido que cada centro constituía un colectivo a analizar separadamente, $y$ por ello creemos que el sentir general de la comunidad estudiantil se percibe mejor teniendo presente la especificidad de cada centro, no la de cada alumno. Asi pues, se hizo un escrutinio sobre la base de cada centro. Los datos porcentuales asi extraídos son los que han servido para elaborar unos datos generales. Es decir, los resultados de cada área provienen de los datos porcentuales de cada centro. Para elaborar estos resultados globales no se ha atendido a los datos absolutos -la suma de cada encuesta y su puesta en común-; no se ha realizado la valoración final independientemente del centro del que procediese. Dado que se ha tenido en consideración la especificidad de los centros educativos, $y$ puesto que no era el mismo el número de encuestados en cada centro, nos ha parecido correcta esta forma de proceder.

De este modo, el valor de la opinión vertida por cada estudiante no ha sido el mismo, y sí el de la voluntad de cada centro, desde su consideración propia.

\section{C) Sistematización del análisis de los resultados en cuatro grandes áreas}

La amplitud del campo de consulta ha sido considerable, puesto que las veintitrés preguntas formuladas configuran un extenso conjunto; las contestaciones a las mismas abarcan realidades heterogéneas. No obstante, estas cuestiones se reconducen a cuatro grandes áreas definibles.

Bien se cuestionaba el grado de conocimiento de elementos básicos de la cultura democrática (derechos humanos, democracia, Constitución, etc.). Bien se intentaba captar la sensibilización del alumnado en torno al respeto real de estos derechos. Asimismo, se interrogaba acerca de diversas inquietudes políticas del alumnado (pena de muerte, xenofobia, culpabilidad de las personas, etc.). Por último, se hacía reflexionar al sujeto encuestado al respeto del tema central que aquí nos ocupa, la necesidad de la enseñanza de los derechos humanos y el principio democrático.

Sin más, a continuación se describe lo recabado sobre cada una de estas áreas, una por una, acompañándose los comentarios con los oportunos cuadros o gráficas, que estimamos de gran utilidad al lector para captar las manifestaciones del alumnado. 


\section{EL DESCONOCIMIENTO DE ELEMENTOS BÁSICOS} DE UNA CULTURA DEMOCRÁTICA

Es evidente que sensibilizar y socializar en favor de los derechos humanos y la democracia no conlleva hacer de los estudiantes unos técnicos jurídicos. No es necesario conocer profusamente la Constitución, saber las diferentes teorías sobre lo que es democracia, no es menester reconocer uno a uno todos los derechos humanos. No, no es necesario pretender una sociedad de juristas. Si bien nunca estará de más todo conocimiento técnico, puede relegarse este saber jurídico a los estudios superiores, a la formación de especialistas de la materia. Lo que en absoluto puede significar esto es el desconocimiento total de los elementos básicos del sistema político democrático: las ideas de Constitución, de democracia, de derechos o las instituciones básicas de este sistema político. Para tener una mínima percepción individual del contexto político, es imprescindible no partir de concepciones erróneas, deformadas. De lo contrario, se forja un sentimiento político y constitucional igualmente erróneo y deforme.

Veamos algún ejemplo: si se identifica la democracia con el mero derecho al voto, no será difícil que quien parte de este reduccionismo piense negativamente de un sistema democrático. Asimismo, si alguien considera que los derechos humanos son los que ostentamos frente a los demás, si no advierte que son eso, humanos, y por ello de todos, se correrá el peligro de que se identifique únicamente la tenencia de unos derechos desde el individualismo, desde el provecho propio de los mismos, no como pauta de respeto. Del mismo modo, de poco sirve abogar por la efectividad de los derechos si no se tiene clara su necesaria relación con la democracia y con la existencia de una Constitución. Flaco favor haremos al régimen democrático constitucional si un ataque al mismo no se concibe como un ataque a los derechos humanos. Para establecer estos nexos resultan ineludibles unas mínimas nociones jurídicas, sin alcanzar el nivel del jurista.

En la misma línea de pensamiento, no es preciso que un estudiante no especializado conozca los mecanismos orgánicos constitucionales, el funcionamiento y composición de cada institución. Sin embargo, si creemos necesario que cualquier persona comprenda que el Parlamento no es meramente «un lugar donde se reúnen los que mandan para insultarse", sino que independientemente de la realidad politica del momento, allí se reúnen las personas en las que el pueblo ha depositado su confianza, quienes nos representan. 
En fin, de una serie de respuestas de la encuesta se deducía necesariamente el conocimiento de estos elementos básicos, su interrelación. No se pretendía que la manifestación fuese técnicamente correcta; se buscaba que la representación mental y emocional de lo cuestionado fuera acorde con el concepto. Además, del tenor de las contestaciones se desprende en ocasiones información diversa. De ahí se pueden atender factores como la vía de conocimiento del alumnado (televisión, escuela), la influencia social y familiar, etc.

Realmènte, en este aspecto del conocimiento por parte de los discentes es donde podemos sentirnos desilusionados en mayor medida. Los resultados de las encuestas que a continuación se exponen, a priori parecerán positivos -las cuotas de conocimiento son, en casos, elevadas-. Ahora bien, el nivel de conocimiento manifestado, la simplicidad de las respuestas, es decir, el elemento subjetivo al que se aludió anteriormente, nos lleva a afirmar la carencia de una mínima cultura democrática. En efecto, se han tomado como aceptables respuestas que, o bien afirmaban conocer lo preguntado sin más explicación, o bien mostraban una muy parca idea.

Del lado positivo, debe reconocerse que si bien el nivel teórico es excesivamente bajo, se compensa éste con un sentir positivo hacia estos elementos. El sentimiento de los alumnos va a menudo por delante de su conocimiento; pese a la generalizada ignorancia, se tiende a valorar positivamente lo relacionado con la democracia y los derechos humanos. Veamos ahora parceladamente lo que se desprende al respecto. Se ha diversificado este conocimiento en conceptos básicos, la interrelación de los mismos y acercamiento a personalidades e instituciones.

\section{A) Grado de acercamiento a los conceptos básicos}

\section{Derechos humanos}

"¿Qué son los derechos humanos? Enumera una lista de los que conozcas». El conocimiento exhibido por los alumnos al contestar esta pregunta resulta quizá el más elevado respecto de las demás preguntas. Más de la mitad del alumnado manifestó una noción aceptable, un tercio una idea mínima, siendo muy pocos los que afirmaban desconocerlos. El nivel de conocimiento aumenta en el caso de los estudiantes que iniciaban la carrera de Derecho. Resulta decisivo percibir un talante positivo de cara a los derechos humanos, se ven como necesarios; así se vislumbra nítidamente en las encuestas. 
En las definiciones se recogen dos coordenadas fundamentales. De un lado, derechos humanos como un mínimo básico vital («son los derechos mínimos de las personas"), derechos que corresponden a todas las personas por su condición de tales, y por tanto por el mero hecho de nacer («son unos puntos a favor que tenemos los seres humanos desde el mismo momento de nuestro nacimiento", "son valores reconocidos universalmente que sirven para cualquier persona»). De otro lado, aparece con semejante intensidad la idea de libertad pública como derecho humano. No se identifica directamente a éstos con la esfera personal (derechos fundamentales), sino con la libertad misma, innata e inalienable ( «son los derechos que nos permiten ser libres", "conjunto de normas por las que el hombre tiene mayor libertad"), $y$, como consecuencia, se da pues esta fuerte identificación de los derechos humanos con las libertades próximas al marco político?. Podemos entender esta circunstancia por el apego a la experiencia del propio país o a lo que, para sus padres y familiares, ha representado el establecimiento de la democracia.

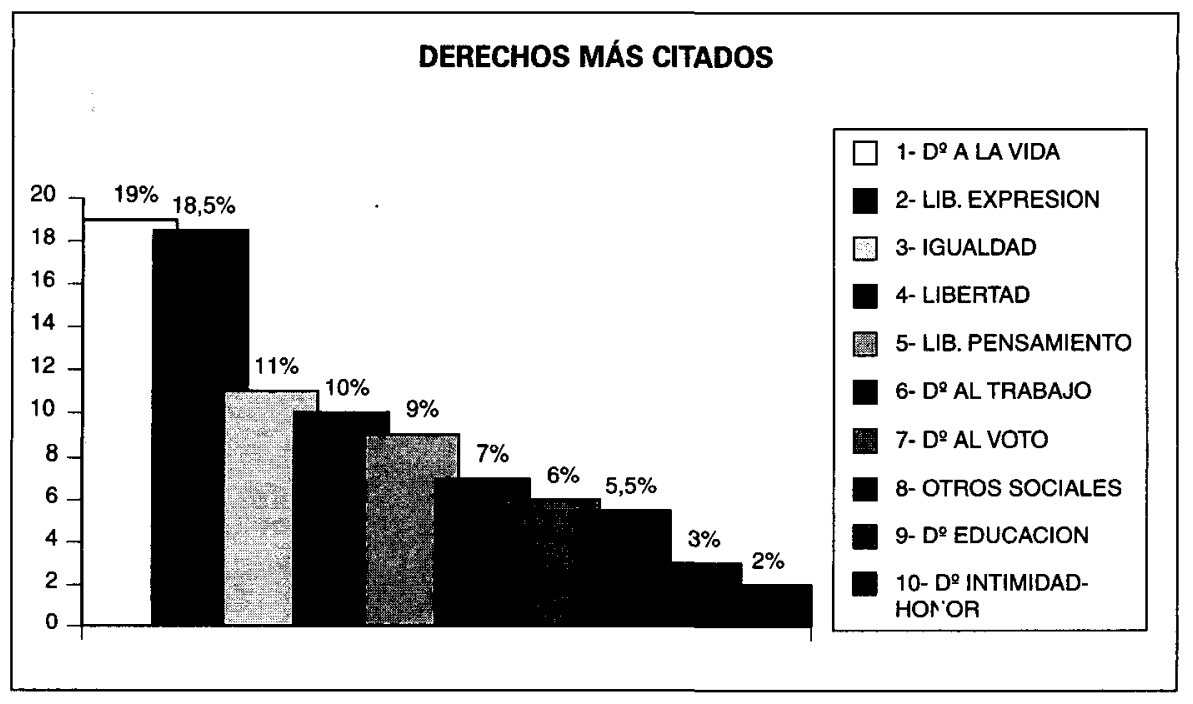

Cuadro n. ${ }^{\circ}$. Derechos Fundamentales más citados por los alumnos. (Pregunta $n .^{\circ} 1$ )

7 Ver al respecto R. SÁnchez FerRiz, Estudio sobre las libertades. Valencia, Tirant lo Blanch, 1995, 2. $\mathrm{ed}$. 
En las definiciones vertidas, al margen de esta doble coordenada fundamental, existen también unas tendencias a concebir estos derechos estrechamente unidos al correlativo deber de respeto a los demás ( "son unas reglas por las cuales toda persona debe respetar y tolerar al resto", "los derechos humanos hacen que las personas sean respetadas y respeten a los demás», "es el respeto al prójimo en todos los sentidos"). Esta connotación por la que debemos apostar, se enfrenta en ocasiones a la ya aludida concepción individualista de los derechos ("lo que todos tenemos para hacer lo que nos dé la gana»). Es significativa también la comprensión de los derechos humanos como pautas de comportamiento de las personas («derechos por los cuales las personas se rigen, para el buen comportamiento", "son una serie de normas básicas que intentan regir el comportamiento social mínimo entre las personas en general»); además cabe resaltar que esta visión se da especialmente en los casos de centros privados. Tal vez sea porque en estos centros es donde la disciplina y las normas de conducta se inculcan en mayor medida $y$, por ello, se establece el positivo nexo entre estas normas $y$ el respeto de estos derechos. Prima asimismo en numerosas respuestas la idea de seguridad y protección de estos derechos, como esfera limitativa de los ataques tanto estatales como del resto de las personas ( "son unas normas para que la gente pueda vivir sin miedo", "derechos para denunciar o reclamar cualquier hecho que no esté bien").

Es ahora momento de hacer una mención especial a la igualdad, a su consideración por el alumnado. Aparece en múltiples ocasiones como principio inspirador de los derechos humanos, bien por ser derechos de todos, universales, bien como elemento de equiparación ("serie de normas establecidas cuyo único y principal motivo de existencia es conseguir un mismo nivel de vida para todo ciudadano del mundo"). Lo significativo es que estas alusiones a la igualdad se encuentran bien diferenciadas por la provinencia de un centro educativo u otro. La igualdad no es aludida en los colegios privados religiosos; por contra, en los centros públicos la citan profusamente como derecho humano. Es insoslayable afirmar, pues, que la percepción de la igualdad se entronca con la condición social del alumno; aquéllos más favorecidos prescinden de ella, mientras que se encuentra bien arraigada en los centros en los que el alumnado no dispone de muchos medios económicos ${ }^{8}$.

a Por motivos obvios de espacio no se pueden incluir aquí los resultados de forma desglosada. No obstante, hay que destacar que en los calificados como religiosos 
Al requerir en la pregunta que se citaran los derechos más conocidos se pretendía percibir cómo manifestaban concretamente el ideal que habían vertido, cuál era el grado de popularidad de los derechos entre los alumnos. El resultado, que se aprecia en el cuadro $n .^{\circ} 1$, confirma lo antedicho. Por una parte, los principios básicos de libertad e igualdad son citados como derechos mayoritariamente y por igual, ocupan el tercer y cuarto lugar. El derecho a la vida es el más citado; se pronuncia esta preferencia en colegios religiosos (tal vez por cierta susceptibilidad ante el tema del aborto). El derecho a la vida es, como sabemos, un derecho de la esfera personal y si bien es el más mencionado, no encontramos ninguno de los de esta naturaleza nombrados de forma significativa. Por contra, la libertad de expresión se encuentra pareja al derecho a la vida en el reconocimiento como derecho humano; además, otras libertades como la de pensamiento se encuentra en un lugar cualificado. Del mismo modo sucede con el derecho al voto. De esta lectura se confirma, pues, el grado de aceptación de esta vertiente política de los derechos humanos. También podemos hacer una lectura de las libertades señaladas: la de expresión, la de pensamiento, por un lado acordes con los sentimientos juveniles de los encuestados; pero, a la vez, son libertades individuales. Libertades como la de asociación o reunión son traídas a colación pocas veces. Sobre este particular, quizá sea -siquiera en una mínima medida-reflejo de la sociedad individualista y masificada en la que vivimos.

Por último, apréciese cómo los derechos prestacionales y sociales ocupan una posición significativa en su consideración como derechos humanos, trabajo, educación, sanidad, vivienda, aparecen citados en no pocas ocasiones. La susceptibilidad ante problemas como el del paro es notable. Lo relevante es que este sentir se va traduciendo, poco a poco, en el arraigo de la concepción de estos derechos como derechos humanos.

\section{Constitución}

No se establecían en la encuesta preguntas directas acerca del conocimiento del concepto de Constitución. Tan sólo se cuestionaba la existencia de un nexo entre la Carta Magna y los derechos humanos (pre-

es nula la referencia a la igualdad, mientras en todos los demás es éste uno de los derechos humanos más citados (del 15 al $20 \%$ ). Es por esta diferencia por lo que la igualdad no ocupa el primer o segundo lugar en la media general. 
gunta $n .^{\circ}$ 2). Más concretamente, la pregunta $n .^{\circ} 17$ interrogaba: $¿$ Sabes lo que la Constitución dice sobre la pena de muerte? El análisis de las contestaciones en torno a estas dos preguntas es suficiente para poder afirmar que no llega a un $10 \%$ los alumnos que tienen una idea clara de lo que es y supone la Constitución (cuadros 2 y 4). La mayoría simplemente conoce su existencia y percibe su importancia. Una vez más debemos confiar en la percepción, la representación emocional positiva, puesto que, realmente, el alumnado no sabe lo que es la Constitución.

Con los datos en la mano, la midad de los encuestados dijo conocer lo dispuesto al respecto de la pena de muerte, manifestando alguna noción sobre la posibilidad de la misma sólo para los tiempos de guerra. La otra mitad se reparte entre quienes se acercan a afirmar o incluso a apostar por qué no está permitido este castigo y quienes reconocen o expresan su total desconocimiento. Estos datos cambian respecto del muestreo realizado en la Facultad; quienes han elegido la carrera de Derecho conocen mayoritariamente lo dispuesto sobre la pena de muerte.

La afirmación del general desconocimiento forma parte en buena medida del citado elemento subjetivo añadido. Así se aprecia, por ejemplo, cuando se indaga el conocimiento de alguna relación entre derechos humanos y Constitución. Si bien la percepción es positiva, como veremos, las explicaciones que revelan el posible nexo son muy pobres. Pocos alcanzan a aclarar que en la Norma Fundamental se reconocen estos derechos; son menos aún los que afirman que ahi se consagran las garantías de su efectividad, o que ahí se regula nuestro sistema político, sistema que necesariamente está orientado hacia el respeto de los mismos.

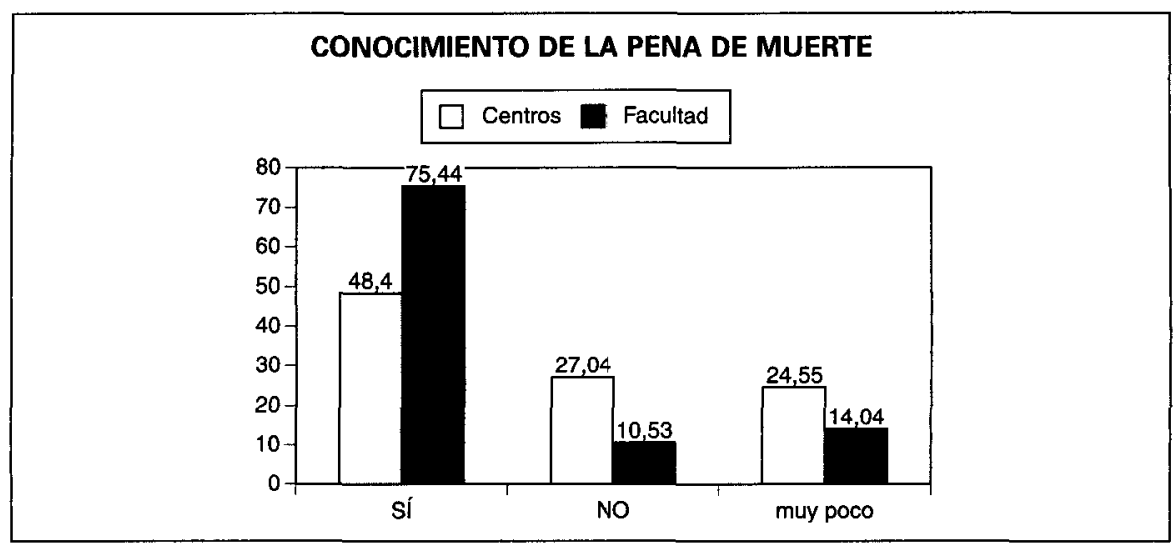

Cuadro $n .^{\circ} 2$ ¿ ¿Sabes lo que la Constitución dice sobre la pena de muerte? (Pregunta $n .^{\circ}$ 17) 


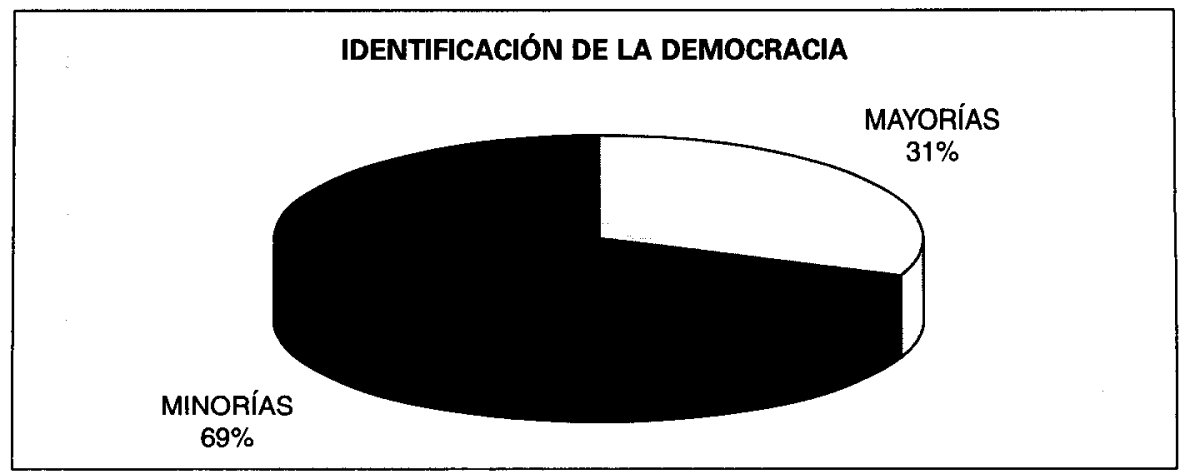

Cuadro.$^{\circ} 3$. ¿A cuál de estas dos ideas crees que se vincula más una democracia? al respeto de minorías y de toda persona/al respeto al poder de las mayorías elegidas. (Pregunta $n .^{\circ} 5$ )

Cuadro $n .^{\circ} 4$. Conocimiento de algunos conceptos básicos

\begin{tabular}{|c|c|c|}
\hline 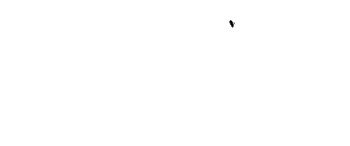 & $\begin{array}{c}\text { TOTAL } \\
\text { CENTROS } \\
530 \text { encuestas }\end{array}$ & $\begin{array}{c}\text { Facultad } \\
\text { Derecho } \\
57 \text { encuestas }\end{array}$ \\
\hline \multicolumn{3}{|l|}{ Constitución } \\
\hline \multicolumn{3}{|c|}{ Conocimiento pena muerte } \\
\hline si & $48,40 \%$ & $75,44 \%$ \\
\hline no & $27,04 \%$ & $10,53 \%$ \\
\hline muy poco & $24,55 \%$ & $14,04 \%$ \\
\hline Total & $100,00 \%$ & $100,00 \%$ \\
\hline \multicolumn{3}{|c|}{ Identificación de la democracia } \\
\hline minorías & $69,08 \%$ & $79,95 \%$ \\
\hline mayorías & $30,91 \%$ & $21,05 \%$ \\
\hline Total & $100,00 \%$ & $100,00 \%$ \\
\hline \multicolumn{3}{|l|}{ Estado Derecho } \\
\hline aceptable & $9,33 \%$ & $24,56 \%$ \\
\hline mínimo & $18,88 \%$ & $0,00 \%$ \\
\hline nada/no contesta & $71,78 \%$ & $75,44 \%$ \\
\hline Total & $100,00 \%$ & $100,00 \%$ \\
\hline
\end{tabular}




\section{Democracia}

Las preguntas 3,4 y 5 , versaban sobre el principio democrático. Al igual que en torno al conocimiento del ideal constitucional, se pueden extraer consecuencias de la lectura del conjunto de los resultados de la encuesta. En esencia, hay que afirmar el reduccionismo al que se somete a la democracia. La idea es sólo formal y procedimental, se reconduce casi exclusivamente al derecho al voto.

La paradoja se da en la pregunta $n .^{\circ} 5:$ "¿A cuál de estas dos ideas crees que se vincula más una democracia? Al respeto de minorías $y$ de toda persona / al respeto al poder de las mayorías elegidas". En este caso al alumno se le daban las opciones a elegir; más que mostrar su conocimiento tenía una oportunidad de mostrar su tendencia personal. Es en este caso, un $70 \%$ no dudaron en identificar a la democracia con el respeto de las minorias; se intensifica esta identificación en los alumnos de la Facultad, alcanzando un $80 \%$ (véanse cuadros 3 y 4). Una vez más es reconfortante apreciar el sentir emocional del alumnado, que marcha distanciado del conocimiento teórico. Se distorsionan los pensamientos al no tener unos conocimientos definidos de la democracia. Seguimos confiando, pues, en lo emocional, cuando unas nociones teóricas serian buen instrumento para arraigar las bondades del sistema democrático. Entendamos que es reconfortante esta identificación de la democracia con el respeto de las minorías, por cuanto estos alumnos se hallan cercanos a la entrada en un mundo masificado en el que el control por la masa puede mostrarse aplastante.

\section{Estado de Derecho}

Las preguntas 4, 5 y 6 trataban de provocar una reflexión o, al menos, llamar la atención sobre el entorno jurídico político que rodea a los jóvenes; no se cuestionaba directamente un conocimiento teórico. En la pregunta 9, desde la abstracción de la pregunta "¿Sabes lo que es un Estado de Derecho?", y dado el carácter técnico de la expresión, se pretendía observar si se vinculaba esta idea al régimen político español vigente (lo que prácticamente nadie hizo) y a qué valores asimilaban con carácter general al Estado de Derecho. Dado el bajo conocimiento de conceptos más populares, como los que ya hemos visto, no es de extrañar que tan sólo una cuarta parte manifestase tener alguna idea al respecto. Realmente, esta cuarta parte afirmaba saber a qué alude la expresión; luego, eran menos los que demostraban tener una leve idea (véase cuadro $n .^{\circ} 4$ ). 


\section{B) Percepción del nexo derechos humanos-democracia-Constitución}

Los derechos humanos son reconocidos abiertamente como positivos; resulta realmente importante identificarlos con la Constitución y con el sistema o principio democrático. Es una vía fundamental de socialización democrática identificar al sistema democrático como el único garante de los derechos humanos. Imprescindible es también reconocer a la Carta Magna como medio fundamental, si no único, de reconocimiento de los mismos. Que la sociedad sea consciente de esta relación supone un resorte ante posibles corrientes antidemocráticas; este conocimiento es ni más ni menos un factor de consolidación democrática. Las preguntas $2 .^{a}$ y $3 .^{a}$ iban dirigidas concretamente a averiguar el reconocimiento de este nudo gordiano por parte del alumbrado.

Una vez más nos enfrentamos al hecho de que se pide poner en relación unos conceptos en buena medida desconocidos. Si partimos de que casi la mitad desconoce aceptablemente estos conceptos, los resultados de estas dos preguntas son francamente esperanzadores. Se reconoce mayoritariamente el nexo aludido, tanto respecto de la democracia como de la Constitución (véanse cuadros 5 y 6), únicamente algo más de una décima parte lo niega expresamente. No obstante, de nuevo la voluntad marcha por delante del conocimiento; el

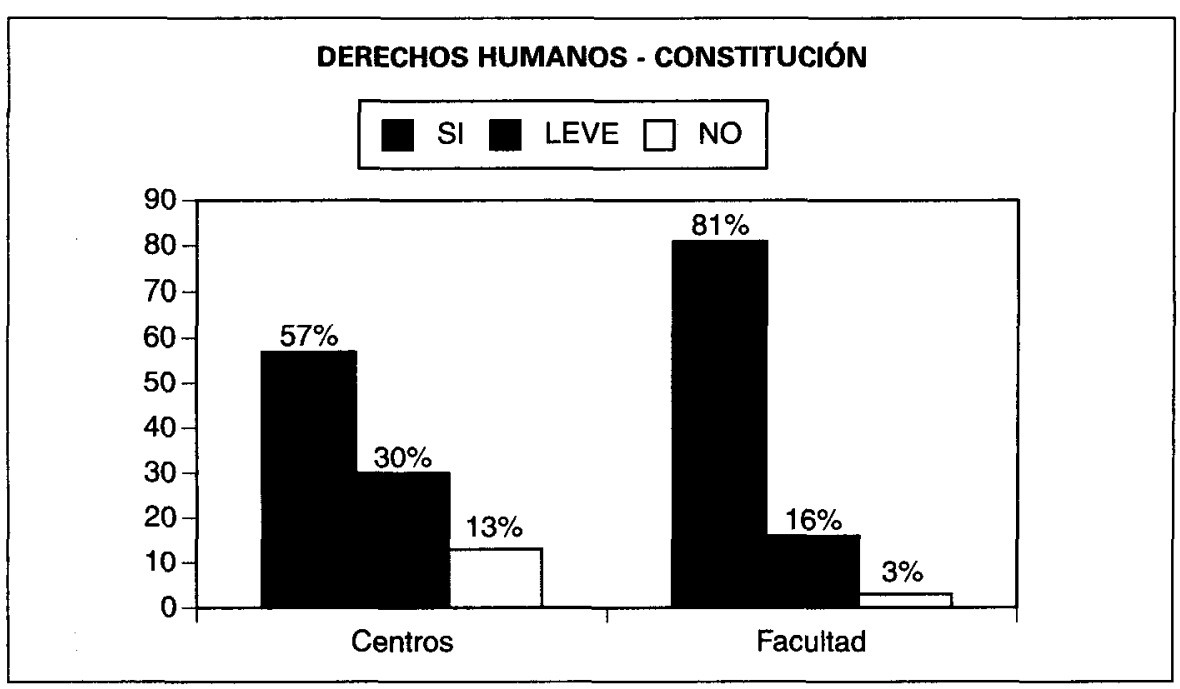

Cuadro $n .^{\circ} 5$. ¿Sabes si hay alguna relación entre la Constitución española y los derechos humanos? 


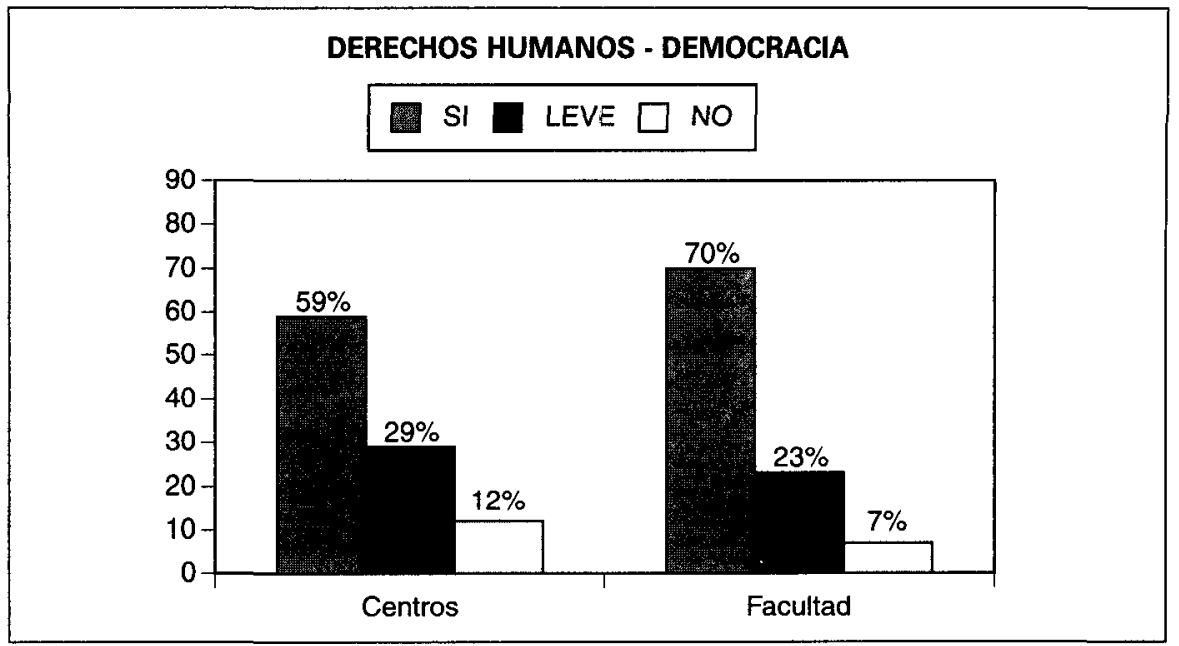

Cuadro $n .^{\circ} 6 . \quad$ ¿Crees que existe alguna relación entre democracia y derechos humanos?

alumno no sabe dar una explicación coherente a su respuesta afirmativa en bastantes casos. Si realmente se conociese lo que supone la Constitución o la democracia la relación entre éstos y los derechos humanos sería inmediata, y para ello no sería preciso adquirir un elegado nivel teórico. $\mathrm{Si}$, como mantenemos, es positivo establecer este nexo, será pues positivo incrementar la enseñanza de estos conceptos; a lo que conmina el art. 27.2 de la Norma Fundamental. Así podemos entender los resultados que se dan en la Facultad de Derecho; quienes eligen esta carrera reconocen en mayor medida esta interrelación. Supera el $90 \%$ el porcentaje de quiénes la afirman. Se presume que estos alumnos son quienes tienen un mayor conocimiento de estos conceptos, al haber elegido esta carrera.

Por un lado, se afirma que los derechos humanos uestán impuestos" en la Constitución, allí "representados", o que la Constitución los "defiende y controla", o "dicta leyes que son derechos y obligaciones". Se ha calificado como un leve reconocimiento del nexo, cuando simplemente se afirma la relación o lo argumentado es erróneo o muy vago. Por otro lado, hay que subrayar alguna respuesta técnicamente aceptable, en el sentido del art. 16 de la Declaración francesa de 1789 -no puede haber Constitución si no se garantizan los derechos-: "Sí, -hay relación- (...) no puede existir un conjunto de leyes básicas sin tenerse en cuenta los derechos humanos". 
En cuanto a la democracia, se percibe en muchos casos la espontaneidad de la relación; se identifica democracia con libertad de expresión, derecho a votar; es decir, con esos derechos que se habian calificado como humanos en una pregunta anterior. Se descubre entonces la relación existente entre ellos. En los centros en los que se subraya la igualdad, se adopta ésta como criterio para identificar derechos humanos con la democracia («no siempre existe relación -entre derechos humanos y democracia-, porque en algunos casos hay discriminación por la raza, el sexo, etc.n, "sí -hay relación-, todos somos iguales, por tanto, todos tenemos derecho al voto...n). Es significativo que los más reacios en reconocer que viven en una democracia son, justamente, quienes mejor captan la relación existente entre ésta y los derechos humanos. Curiosamente, son éstos mismos los que habian mostrado un mayor conocimiento del concepto de derechos humanos en la primera pregunta. Una sociedad bien conocedora de estos conceptos básicos quizá suponga una sociedad más reivindicativa. Volveremos sobre esta cuestión.

\section{C) Conocimiento de instituciones y personalidades}

La pregunta $n .^{\circ} 8$ sugería al alumno que señalase "...de entre estas instituciones $y$ organizaciones aquellas que conozcas $y$ sepas para qué sirven: Parlamento, Defensor del Pueblo, Fiscal, ONU, Consejo de Europa y Amnistía Internacional». La referencia institucional que se contiene nos ha permitido conocer si se dispone de información sobre dichas instituciones que guardan relación con los derechos humanos (nacionales e internacionales) y, consiguientemente, si muestran algún interés por ellas. Al responder los estudiantes to que entienden por sus fines nos permite, además, descubrir el medio por el que obtienen la información. De otro lado, la inclusión en la pregunta n. 13 de cuatro nombres muy significativos en la más reciente historia de la defensa de los derechos humanos pretende obtener información sobre si se conocen tales personajes y su labor en pro de los derechos.

En líneas generales, el tenor general es el de un mayoritario conocimiento. Lo negativo es quizá la calidad de dicho conocimiento. Como se puede apreciar en los cuadros 6 y 7 , el índice de conocimiento más elevado corresponde al Parlamento y la ONU (rondando el $80 \%$ ). No es difícil hacerse una idea de cuál es la función del Defensor del Pueblo (y así lo exponen dos terceras partes); el conocimiento real de esta institución es bastante reducido. Como era de esperar, el Consejo de Europa sólo es conocido por un 15\%, siendo confundido con la Unión Eu- 
ropea. Tampoco es muy popular la organización Amnistía-Internacional, si bien, una leve idea de la misma la tiene al menos un $45 \%$.

Como ya se ha indicado, es preocupante la calidad del conocimiento que se muestra en las contestaciones. Más que conocer, se tiene una referencia. Se ha oido hablar de estas instituciones, pero el cauce de transmisión no parece ser la escuela; la percepción de estas instituciones proviene seguramente de la televisión. La cultura televisiva es patente; se manifiesta significativamente en torno a la figura del Fiscal; de la ONU, del Parlamento, etc. Como consecuencia, la idea de los estudiantes está bastante deformada (Parlamento como "lugar donde los políticos se reúnen para discutir e insultarse y nos mandan", Fiscal como "el que acusa de asesinatos", ONU "como organización de países que ayudan al tercer mundon). Es deseable que las instituciones fundamentales no sean deformemente conocidas; para ello, parece necesario apostar por que el cauce por el que se perciba su significado sea mayormente académico.

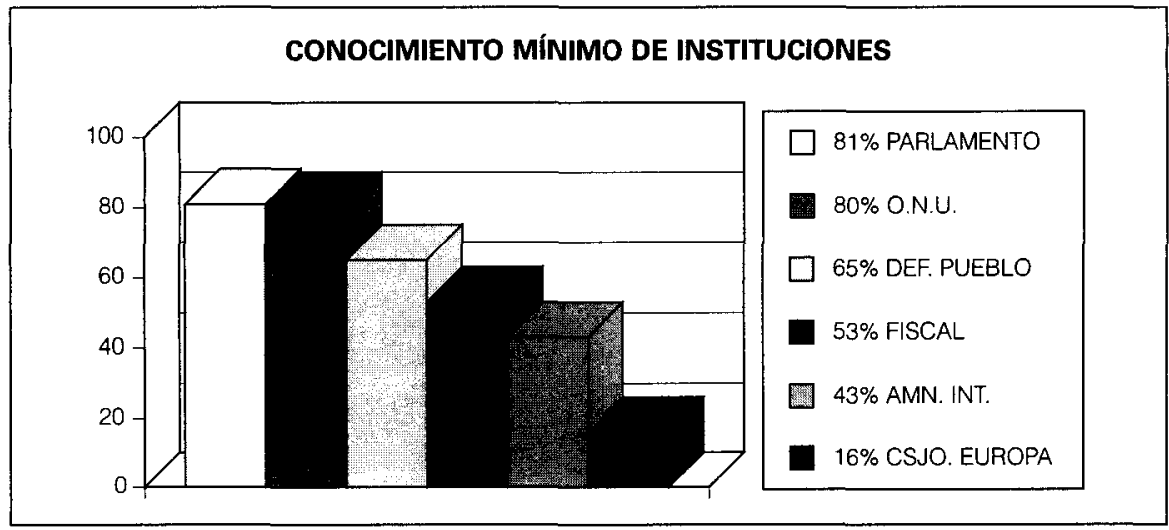

Cuadro $n .^{\circ}$ 6.B. Grado mínimo de acercamiento a instituciones y organizaciones

Se cuestionaba en la pregunta $\mathrm{n} .^{\circ} 13$ si "¿Conoces $y$ sabes qué hacen/hicieron? Martin Luther King, Rigoberta Menchu, Teresa de Calcuta, Gandhi».

Entendimos por nuestra parte que los citados han sido personalidades muy relevantes en la defensa de los derechos humanos. Una cultura democrática necesariamente tiene que hacerse eco de ellos. Se aprecia en las encuestas (ver cuadro $n .^{\circ} 7$ que estos porcentajes son 
Cuadro n. $^{\circ}$. Conocimiento de instituciones y personalidades por parte del alumnado

\begin{tabular}{|c|c|c|}
\hline & $\begin{array}{l}\text { TOTAL CENTROS } \\
530 \text { encuestas }\end{array}$ & $\begin{array}{l}\text { FACULTAD } \\
57 \text { encuestas }\end{array}$ \\
\hline \multicolumn{3}{|l|}{ Instituciones, pregunta 8} \\
\hline \multicolumn{3}{|l|}{ Parlamento } \\
\hline mínima idea & $81,51 \%$ & $100,00 \%$ \\
\hline no idea/muy errónea & $18,49 \%$ & $0,00 \%$ \\
\hline \multicolumn{3}{|l|}{ Defensor Pueblo } \\
\hline mínima idea & $64,48 \%$ & $92,98 \%$ \\
\hline no idea/muy errónea & $35,52 \%$ & $7,02 \%$ \\
\hline \multicolumn{3}{|l|}{ Fiscal } \\
\hline mínima idea & $53,06 \%$ & $85,96 \%$ \\
\hline no idea/muy errónea & $46,94 \%$ & $14,04 \%$ \\
\hline \multicolumn{3}{|l|}{ ONU } \\
\hline mínima idea & $80,35 \%$ & $96,49 \%$ \\
\hline no idea/muy errónea & $19,65 \%$ & $3,51 \%$ \\
\hline \multicolumn{3}{|l|}{ Consejo Europa } \\
\hline mínima idea & $16,39 \%$ & $15,79 \%$ \\
\hline no idea/muy errónea & $83,61 \%$ & $84,21 \%$ \\
\hline \multicolumn{3}{|l|}{ Amnistía-Internacional } \\
\hline mínima idea & $43,08 \%$ & $68,42 \%$ \\
\hline no idea/muy errónea & $83,61 \%$ & $84,21 \%$ \\
\hline \multicolumn{3}{|l|}{ Personalidades, p. 13.} \\
\hline \multicolumn{3}{|l|}{ M. L. King } \\
\hline minima idea & $80,07 \%$ & $96,49 \%$ \\
\hline no idea/muy errónea & $19,93 \%$ & $3,51 \%$ \\
\hline \multicolumn{3}{|l|}{ R. Menchu } \\
\hline mínima idea & $20,26 \%$ & $24,56 \%$ \\
\hline no idea/muy errónea & $79,74 \%$ & $75,44 \%$ \\
\hline \multicolumn{3}{|l|}{ T. Calcuta } \\
\hline mínima idea & $79,15 \%$ & $98,25 \%$ \\
\hline no idea/muy errónea & $20,85 \%$ & $1,75 \%$ \\
\hline \multicolumn{3}{|l|}{ Gandhi } \\
\hline mínima idea & $82,38 \%$ & $100,00 \%$ \\
\hline no idea/muy errónea & $17,62 \%$ & $0,00 \%$ \\
\hline
\end{tabular}


mayoritariamente conocidos (en general por un $80 \%$ ). Se conocen mejor que las instituciones, si bien no superan el $20 \%$ los que mostraban tener un acercamiento serio a la obra de estas personalidades. Es significativo el desconocimiento de la figura de Rigoberta Menchu, premiada con el Nobel de la Paz por su labor en defensa de los pueblos indígenas. No más de un $20 \%$ muestra algún grado de conocimiento. Una lectura que ello puede ser que la lucha en favor de los derechos ha adquirido tal envergadura, tal internacionalización, que difícilmente pueden volver a destacar personas de manera individual, como lo hicieron los otros, apareciendo como un imperativo trabajar en equipo. Frente a individualismos como los de antaño, gran parte de los esfuerzos en esta ardua tarea se canalizan a través de organizaiones internacionales.

Es muy superior el grado de conocimiento, tanto de instituciones como de personalidades, de los que eligen Derecho como carrera. Es superior cuantitativamente, en la mayoría de los casos rozan el $100 \%$ los que responden acertadamente. Además, cualitativamente, estos alumnos están bastante más acertados en sus consideraciones. En todo caso, el Consejo de Europa y Rigoberta Menchu siguen siendo los grandes desconocidos.

\section{SENSIBILIZACIÓN DEL ALUMNADO EN TORNO AL RESPETO REAL DE ESTOS DERECHOS}

Las cuestiones 11 y 12, así como la 22, enfrentaban al encuestado con la realidad en que viven. Los dos primeros casos invitan a reflexionar sobre el ámbito más amplio que puedan conocer (dentro y fuera de España); en este caso su percepción les vendría dada por los medios de comunicación o por la opinión de sus mayores. En la pregunta $n .^{\circ} 22$ se les permitió precisar bastante más sobre su experiencia o vivencia de lo que sea y de cómo se aplica la igualdad. No sólo se les planteaban supuestos concretos referidos a grupos sociales determinados (homosexuales, extranjeros, disminuidos,e tc.), sino también se les preguntaba sobre su entorno, es decir, sobre una realidad que directamente podian observar.

En primer lugar, se indagaba si "¿Crees que hoy en día se respetan los derechos humanos? En caso negativo, te atreverias a dar alguna solución?" Un 70\% no dudó en negar el respeto a los derechos humanos (cuadros 8 y 10). Con la formulación de la pregunta también se perseguía averiguar a quién atribuyen los estudiantes la violación de los mismos. Se destaca que se violan por el poder, pero también algu- 
nos se refieren a agresiones por las personas, como por ejemplo, el caso del terrorismo, los abusos a menores, etc. Asimismo cifran al poder como el único capaz de solucionar este problema del respeto a los derechos. Mientras otros apuntan una solución en la represión, no son pocos los que ven el problema en las mismas personas, aduciendo que se precisa educación, cultura y tolerancia.

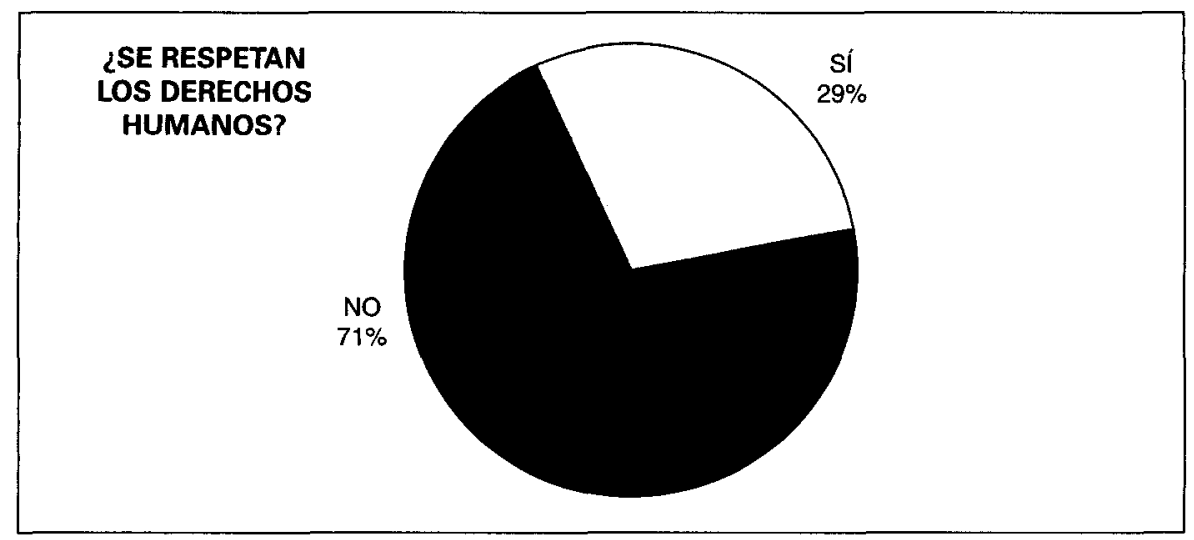

Cuadro $0^{\circ} 8 . \quad$ ¿Crees que hoy en día se respetan los derechos humanos?, pregunta n. ${ }^{\circ} 11$

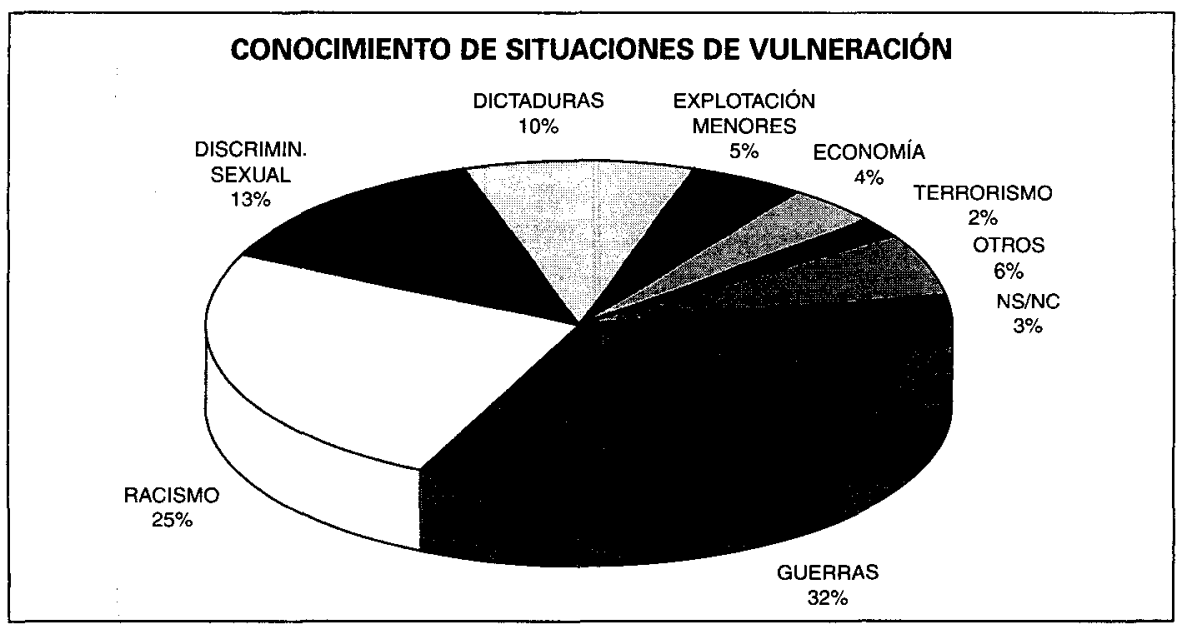

Cuadro $n .^{\circ} 9 . \quad$ ¿Cuántas situaciones actuales, dentro Y fuera de España, puedes recordar de vulneración de los derechos humanos?, pregunta $n .^{\circ} 12$ 
Al responder a la pregunta de "¿Cuántas situaciones actuales, dentro y fuera de España, puedes recordar de vulneración de los derechos humanos?", podemos percibir la ya esmentada influencia de la televisión. El problema de los medios de comunicación es que al mismo tiempo que nos informan sobre las violaciones de derechos en cualquier parte del mundo, presentan el riesgo de ofrecer una visión sesgada de la materia, y con frecuencia se piensa erróneamente que tales vulneraciones sólo se producen en el denominado Tercer Mundo. A éste pertenecen mayormente las situaciones descritas (cuadros 9 y 11). Así pues, son las guerras la vulneración de derechos más aludida; tras éstas se encuentran las discriminaciones racial y sexual, luego son las dictaduras y la explotación a menores citadas de modo significativo.

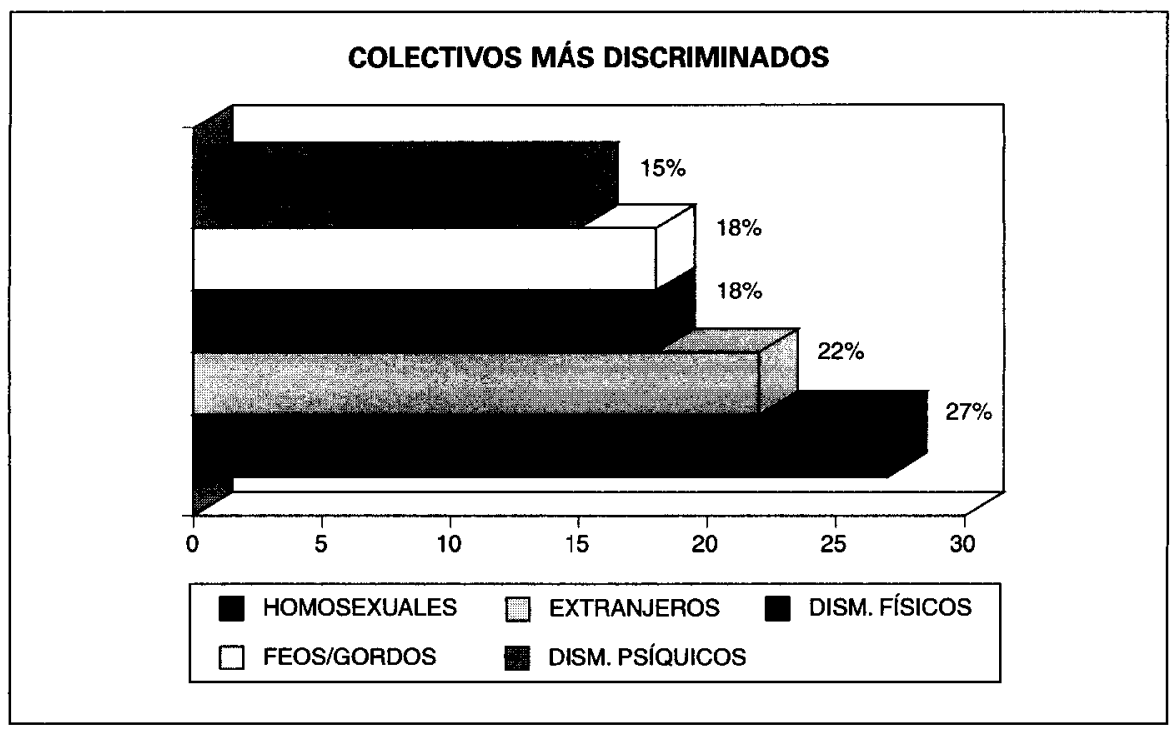

Cuadro $n .^{\circ}$ 10. Percepción de la discriminación del entorno

Ha de hacerse notar, por tanto, que es un error la autocomplacencia, pensar que la falta de respeto a los derechos humanos es una cuestión ajena a los países desarrollados, en los que cada día se violan más. Si bien los atentados más graves se dan en las situaciones citadas, no hay que distanciarse hasta el punto de no apreciar atentados en el entorno, de lo contrario se llega a hacer manifestaciones como: "Recuerdo pocas -violaciones-, porque veo poca televisión". Es positivo el hecho de que se identifique en segundo y tercer lugar a la discri- 
minación racial y sexual como atentados a los derechos humanos. Como se verá más tarde, si en algo parece haber emergido una buena socialización ha sido en el principio de no discriminación.

Cuadro . $^{\circ}$ 11. Percepción del respeto de los derechos humanos y consideración de los colectivos más discriminados

\begin{tabular}{|c|c|c|}
\hline & $\begin{array}{c}\text { TOTAL } \\
\text { CENTROS } \\
530 \text { encuestas }\end{array}$ & $\begin{array}{c}\text { Facultad } \\
\text { Derecho } \\
57 \text { encuestas }\end{array}$ \\
\hline \multicolumn{3}{|c|}{ ¿Se respetan los derechos humanos?, pregunta 11.} \\
\hline si & $29,31 \%$ & $28,07 \%$ \\
\hline no & $70,69 \%$ & $71,93 \%$ \\
\hline Total & $100,00 \%$ & $100,00 \%$ \\
\hline \multicolumn{3}{|c|}{ Situaciones de Vulneración, pregunta 12.} \\
\hline guerras & $32,82 \%$ & $18,18 \%$ \\
\hline discrim. racial & $24,52 \%$ & $27,27 \%$ \\
\hline discrim. sexual & $13,30 \%$ & $0,00 \%$ \\
\hline dictaduras & $9,90 \%$ & $9,09 \%$ \\
\hline explotación menores & $4,51 \%$ & $6,06 \%$ \\
\hline economía & $3,76 \%$ & $12,12 \%$ \\
\hline terrorismo & $2,02 \%$ & $0,00 \%$ \\
\hline$n s / n c$ & $3,41 \%$ & $0,00 \%$ \\
\hline otros & $6,76 \%$ & $21,21 \%$ \\
\hline Total & $100,00 \%$ & $100,00 \%$ \\
\hline \multicolumn{3}{|c|}{ Discriminación del entorno, pregunta 22} \\
\hline homosexuales & $27,27 \%$ & $30,23 \%$ \\
\hline extranjeros & $21,92 \%$ & $32,56 \%$ \\
\hline dism/psiquicos & $18,18 \%$ & $11,63 \%$ \\
\hline feos y gordos & $17,75 \%$ & $16,28 \%$ \\
\hline dism/físicos & $14,88 \%$ & $9,30 \%$ \\
\hline Total & $100,00 \%$ & $100,00 \%$ \\
\hline
\end{tabular}

En la pregunta $n .^{\circ} 22$, se interrogaba al alumno la percepción personal de su entorno como discriminador. Se solicitaba que indicara si notaba algún trato diferencial a diferentes colectivos usualmente discrimi- 
nados. En esta ocasión, aproximadamente tres cuartas partes del alumnado percibían este trato discriminador a alguno de los colectivos citados (cuadros 10 y 11). Como se aprecia en el cuadro, se coincidió en considerar al colectivo homosexual como es más discriminado. Tras él, y ya sin diferencias importantes se consideraba a los extranjeros, disminuidos psíquicos, obesos y feos $y$, por último, a los disminuidos físicos.

\section{ASPECTOS DE MADUREZ O INQUIETUD POLÍTICA}

Hasta el momento se han tratado aquellas cuestiones de la encuesta que se aproximaban al grado de conocimiento por parte del alumnado de una serie de realidades y conceptos (democracia, Constitución, derechos humanos, la situación de estos en el mundo, etc.). El otro gran área de análisis giraba ya en torno a percepciones más personales del discente. Se brindaba la oportunidad de expresar la propia actitud personal de los encuestados. Bien ante hipótesis que cotidianamente se reciben a través de los medios de comunicación (pena de muerte, culpabilidad de las personas, actual democracia), bien ante casos reales concretos que, en ocasiones, no eran más que la propia experiencia del centro al que pertenecian (convivencia con gitanos).

Haciendo una lectura rápida de los resultados, éstos nos ofrecen una cara y una cruz. Por un lado, preocupa el grado de descontento con el sistema político actual. Un tercio del alumnado negó vivir en democracia. No sólo mostraba descontento con el régimen actual, cosa que hizo buena parte del resto, sino que negó la democraticidad del mismo. También estimamos negativo que una importante mayoría esté a favor de la pena de muerte. Del lado positivo, hay que percibir una importante socialización igualitaria. Especialmente por lo que respecta al calado de sentimientos antixenófobos entre nuestra juventud, entendamos los resultados como muy positivos. Nuestros jóvenes alumnos se posicionan muy claramente en una tajante negación al racismo. Incluso, al tratar de la experiencia más cercana, cuando se ha de valorar la realidad inmediata (situación de los extranjeros en España, convivencia con la raza gitana), se mantienen bastante firmes las afirmaciones antixenófobas.

Resulta muy interesante apreciar en este conjunto de preguntas el ya aludido elemento subjetivo añadido. Independientemente de los datos objetivos que se observan en los cuadros, al contestar estas preguntas el alumnado deja entrever un descreimiento en el sistema, un desinterés y apatía por lo político alarmante, también se refleja un im- 
portante individualismo. Se ha apreciado también algo muy importante: del mismo modo que individualismo actual se deja entrever, son numerosas las críticas realizadas en contra de éste. Está latente un sentimiento de querer compartir, participar, una tensión positiva del alumno que él mismo cree imposible de realizar, descarga las culpas bien en el poder, bien en la sociedad en general.

Quizá una cultura democrática podría hacer conjugar estas dos tensiones, en apariencia opuestas. Una educación democrática podría hacer aprovechar la energía de quienes desean participar en una verdadera participación y acción democrática. Por un lado, existe este desinterés y descreimiento político, que toman la forma de individualismo como rechazo. Por el otro lado, esta tensión positiva hacia la participación y la solidaridad. El joven hà de tener una enseñanza que le haga partir de la base de que la democracia es perpetuamente imperfecta, que es un bien que se construye día a día, y que eso es tarea de todos. El joven ha de percibir realmente que es la democracia el único sistema que puede hacerle participar, el único sistema que respeta esos derechos humanos que considera positivos, ha de entender que la Constitución reconoce tanto estos ideales como los medios para que se puedan llevar a cabo. La percepción de estas ideas por el alumnado no pueden permanecer ajenas a la enseñanza, si se confían sólo a cauces distintos, como los medios de comunicación, el peligro de deformación es patente.

\section{A) Sobre el actual sistema democrático y el sentimiento de ciudadanía}

Por medio de dos cuestiones se valora a continuación tanto la percepción que se tiene del actual régimen político cuanto la personal consideración del alumno dentro de la sociedad en que vive, su sentimiento como ciudadano. El alumnado, incluido el que iba a comenzar estudios de Derecho, está descontento del régimen político, si bien, este enorme grado de insatisfacción parece ser la exteriorización del desagrado por no poder participar más en la sociedad, a la que le gustaría estar más vinculado. También es relevante la circunstancia de que quienes mayores conocimientos políticos muestran son justamente los más críticos con el sistema.

Cuando se habló sobre el conocimiento de la noción de democracia nos servimos en buena medida de lo que respondía el alumnado a la siguiente pregunta: "¿Crees que vives en una democracia? ¿Por qué?». Se asociaba la idea de democracia fundamentalmente al derecho al voto; también se ponía en relación con la más conocida de las li- 
bertades públicas -la libertad de expresión-, asi como con la igualdad. En todo caso, insistimos, la visión de democracia parecía bastante reduccionista. A la hora de calificar el sistema actual-ver cuadro n. ${ }^{\circ} 12-$, un tercio de los encuestados niegan que sea democrático. Aún es más, entre quienes afirman que el actual sistema es democrático, un $20 \%$ muestra claramente su descontento. No parece, a priori, muy positivo que más de la mitad del alumnado niegue la democraticidad del sistema o plantee sus serias dudas. Podría ser que, ciertamente, no vivamos en un régimen democrático, pero más bien parece que no se valore lo positivo del sistema político actual.

La democracia no es sino una lucha permanente y su existencia es frágil, reversible, susceptible de corrupción, tanto en sociedades en las que se acaba de implantar como en aquéllas donde los derechos son ya centenarios. Parecen no ser asumidos como necesarios algunos males menores a los que conlleva este sistema. Si bien en democracia existe un importante grado de descontento, de ahí a negar que se vive en este modelo resulta peligroso. Para lograr que el alumnado valorase más positivamente el régimen actual, se debe explicar lo que es una democracia, lo que no es una democracia, lo que puede pasar cuando no hay una democracia; es decir, resulta necesaria su socialización.

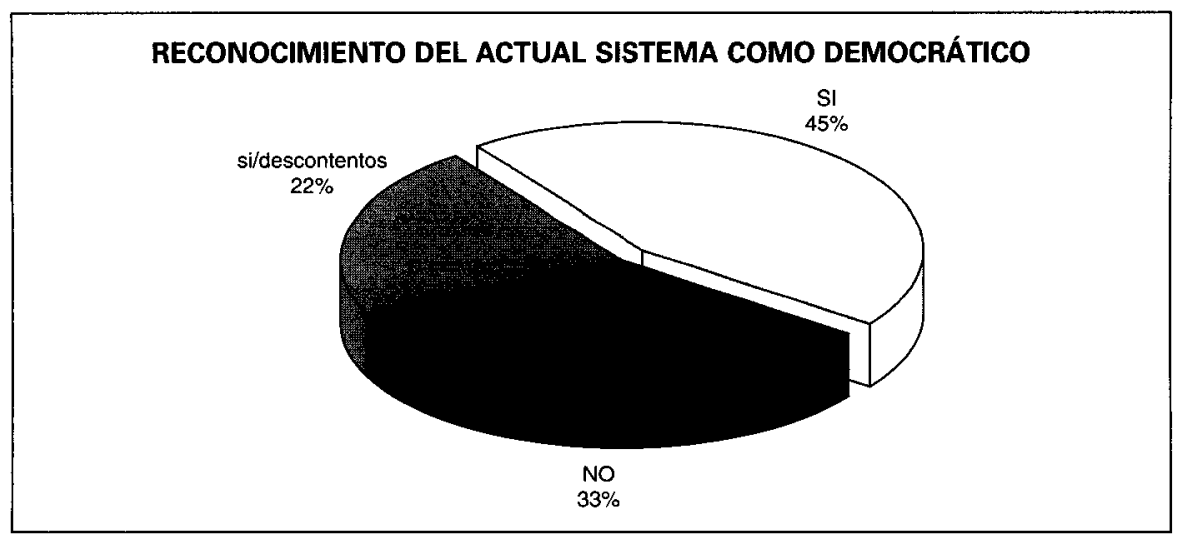

Cuadro $.^{\circ} 12 . \quad ¿$ Crees que vives en una democracia? ¿Por qué? Pregunta $n .^{\circ} 4$

Aunque suene paradójico, podemos entender como más peligroso el número de personas que afirman que el sistema es democrático, que quienes lo niegan o manifiestan su disconformidad. Son estos últimos quienes muestran en el global de la encuesta unos mayores co- 
nocimientos. Es decir, los que no dudan en afirmar que vivimos en una democracia son, en muchas ocasiones, los que reducen a ésta como derecho al voto, los que desconocen lo que es la Constitución, etc. Del lado opuesto, quienes se muestran más críticos son, en muchos casos, los que tienen un mayor conocimiento de estos mismos conceptos. Es posible, pues, que al poder no le interese realmente educar en tus elementos básicos dado que, a mayor conocimiento menos conformismo, más reivindicación.

El poder democrático no puede seguir cayendo en este simplismo, el de no fomentar una cultura democrática y de los derechos para evitar así una sociedad más inconformista. Este poder no debe olvidar que la actual situación de falta de cultura democrática a lo que conlleva es a dudar del propio sistema democrático, como vemos en la encuesta. La democracia se ha de nutrir de inconformistas, de quienes creyendo en los principios democráticos, realicen la lucha continuada que supone trasladar estos principios a la realidad. Si no se lleva $c$ abo esta socialización, las críticas en vez de fomentar el sistema democrático, lo que suponen es luchar en su contra.

Las contestaciones a la cuestión $n^{\circ} 6$, vislumbran una notoria vocación social del alumnado. Ante la pregunta "¿Te sientes ciudadano? ¿Qué significa para ti?", prácticamente un $90 \%$ contestó afirmativamente, y más de la mitad de ellos entendian que ser ciudadano era algo positivo. Se identifica la ciudadanía bien con la tenencia de derechos, bien con la igualdad, bien con los concretos derechos políticos. Pero lo que especialmente prima es la identificación de la ciudadanía con la participación en los asuntos de la ciudad y de la sociedad. Aún es más, se pone el acento en un valor no aparecido hasta ahora, cual es la solidaridad («sí, para mí ser ciudadano es poder ayudar a otros que lo necesitan, conviviendo y sabiendo entender y convivir», "sí, estar cuando haga falta a alguien y viceversan). Sólo un reducido número de estudiantes, un $14 \%$, se excluian de la ciudadanía, siendo en muchos casos quienes mostraban así su deseo de mayor participación. No fueron pocos, casi un $35 \%$, quienes entendían la ciudadanía como una aséptica pertenencia a la ciudad, o simplemente manifestaban que comprenderse como ciudadano no tenía significado positivo.

\section{B) Pena de muerte y culpabilidad de la persona}

Los alumnos habían manifestado durante la encuesta el carácter positivo de los derechos humanos. Había que ver hasta qué punto este 
sentimiento mayoritario era coherente consigo mismo. Se interrogó acerca de la aceptación de la pena de muerte y cuándo se consideraba culpable a una persona. Desde el punto de vista del Estado de Derecho y del más fundamental derecho a la vida, había que estar en contra de la pena de muerte $y$, además, ensalzar a la figura del juez como el único capaz de declarar la culpabilidad de una persona. En ambos casos las contestaciones fueron del signo opuesto. (Véase cuadro $n .^{\circ} 13$ ).

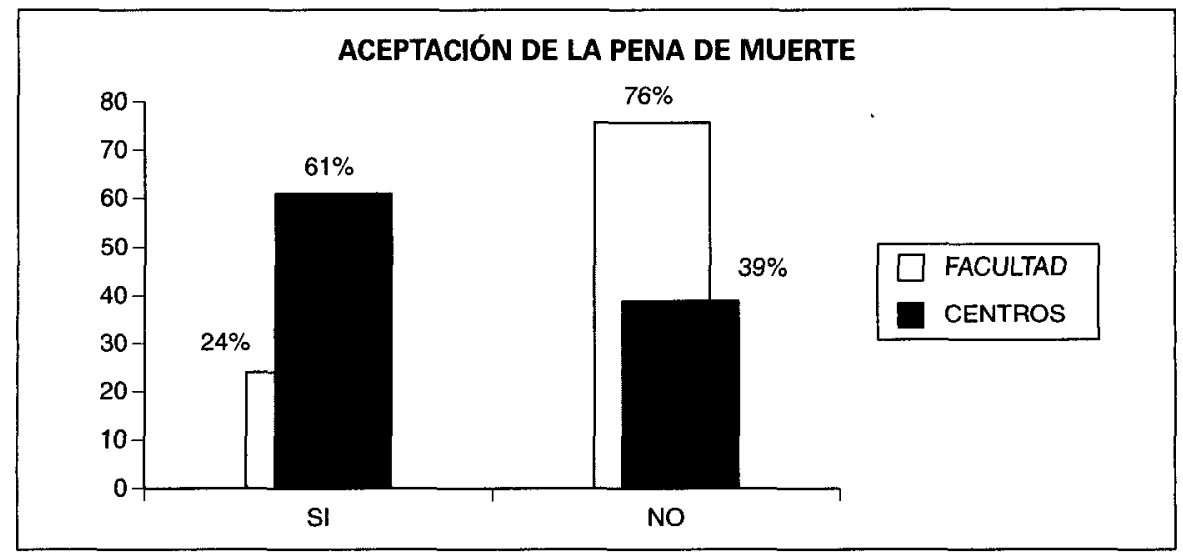

Cuadro $.^{\circ} 13 . \quad$ ¿Estás a favor de la pena de muerte?

Pregunta 16

Un $60 \%$ del alumnado está a favor de la pena de muerte, si bien la restringe para casos de terrorismo, violación o crimenes muy graves. Solamente un $40 \%$ excluye toda posibilidad de pena de muerte, en la coherencia del respeto al derecho a la vida por el que, como derecho humano, ha apostado. El tema es, como sabemos, socialmente controvertido. Pese a la visceralidad a la que se presta esta polémica, es muy posible que una socialización de los derechos humanos y del respeto de los mismos hasta las últimas consecuencias invirtiese la balanza de los que están a favor o en contra de la pena de muerte. Hacer ver que es éste uno de los precios que hay que pagar por un Estado de Derecho, así como la conveniencia de pagarlo es una tarea educativa en la que ha de profundizarse. Una muestra de que un mayor conocimiento puede conducir a un mayor respeto por los derechos humanos, la representan los que eligieron Derecho como carrera. Sólo una cuarta parte se decanta a favor de la pena de muerte, mientras la gran mayoría se muestra contraria. 
En la misma línea se planteó la siguiente pregunta "Consideras culpable a una persona, antes del juicio, sin esperar sentencia: cuando tú mismo eres testigo del hecho presuntamente delictivo / cuando lo lees en la prensa o lo ves en la TV / nunca antes de que el juez se pronuncie». Como parece razonable, una gran mayoría -el 70\%- manifestó culpar a una persona si había sido testigo presencial, un $20 \%$ reconocía expresamente que pese a su testimonio, no consideraría culpable a nadie hasta que un juez así lo declarase, como corresponde a un Estado de Derecho. En este caso, la sensibilidad existe, aunque no se sepan fijar los conceptos. Es destacable y positivo que sólo un $10 \%$ considerase culpable a una persona porque así lo presentasen los medios de comunicación.

\section{C) Interdicción de la xenofobia en las aulas, la apuesta por la tolerancia}

Si de alguna de las conclusiones de estas encuestas podemos estar satisfechos es, sin duda, de la negación del racismo por el alumnado. Como se ha hecho alusión en distintos apartados de este análisis, el sentimiento de igualdad es bastante patente entre los encuestados (especialmente en los centros laicos). Se relaciona la igualdad tanto con los derechos humanos, como con la Constitución, con la democracia. Este sentimiento igualitario se manifiesta específicamente en la práctica unanimidad en el sentimiento antixenófobo -en todos los centros-. Es quizá éste el mejor resultado educativo que se aprecia en relación con el art. $27.2 .^{\circ}$ de la Constitución española. En una época donde parece que acecha una corriente racista en occidente, que se puede afincar en España por la llegada masiva de inmigrantes magrebíes y el rechazo a éstos, el valor de este sentimiento antixenófobo es crucial -véanse cuadros 14 y $15-$.

Se ponía a prueba éste en tres preguntas; quizá la más sencilla de responder era la pregunta $\mathrm{n} .^{\circ} 18$ "¿Te casarías con una persona de otra raza"? No más del $5 \%$ negaron la posibilidad de hacerlo. Tres cuartas partes de los alumnos no ponían condición alguna al afirmar que sí se casarian. La contestación usual y desenfadada era la de "¿por qué no?" A la quinta parte restante, que hemos calificado como "sí, pero", ciertamente no se le puede considerar como racista; las condiciones que expresaban para casarse con alguien de otra raza, lejos del color de la piel, giraban en torno a que exigirian un respeto por parte de la otra raza (culturas musulmanas machistas). Otras de las razones esgrimidas como condicionamiento era la economía. Ciertamente, estas consideraciones económicas, criticables o no, no pertenecen a la esfe- 
ra del sentimiento racista de una persona. Algún alumno hubo incluso que llegó a calificar la pregunta como racista, y por ello se negó a contestar; otro, ciertamente extremado, contestó que "de raza son los perros, las personas son de diferente categoria étnica».
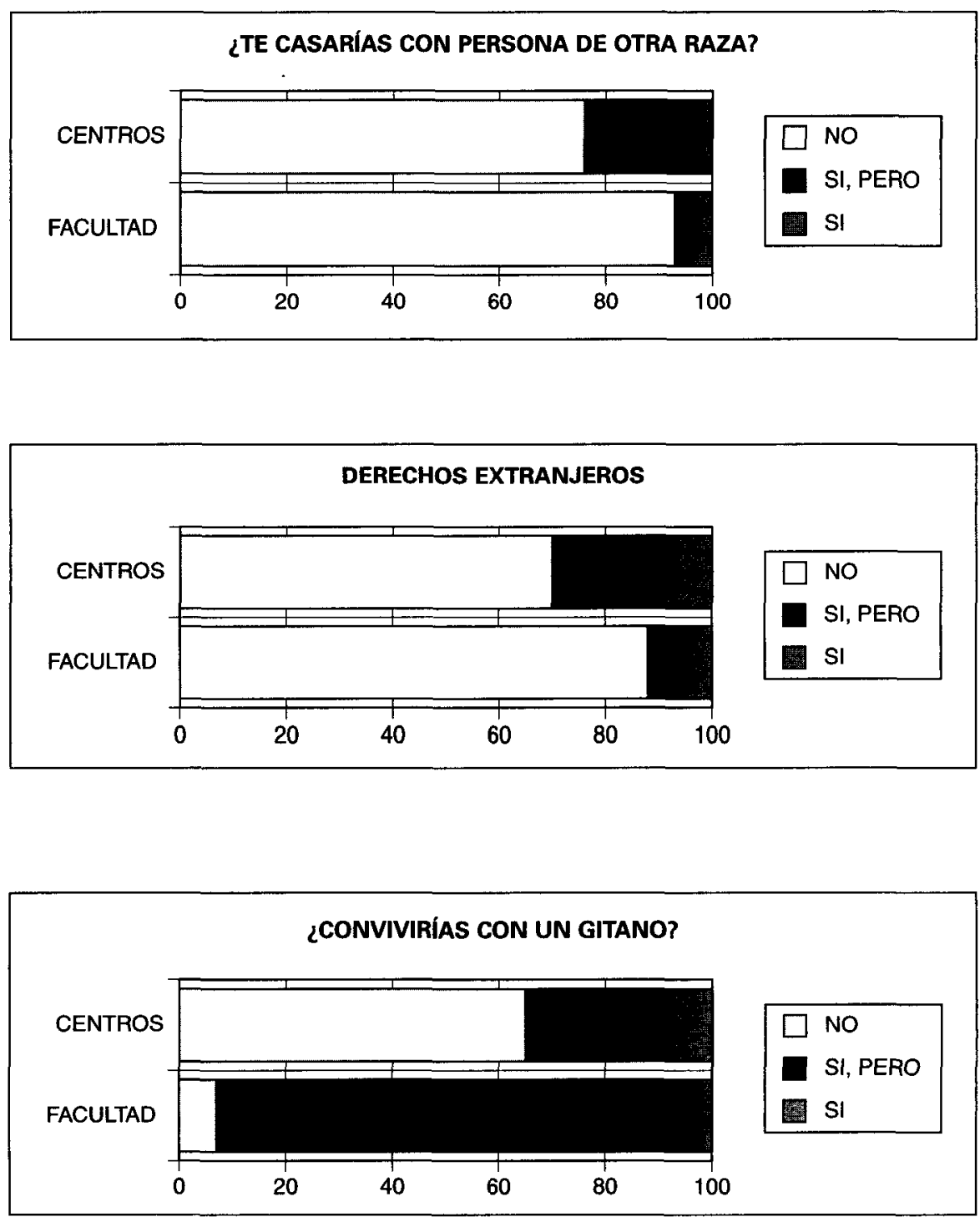

Cuadro . $^{\circ} 14 . \quad$ Nuestros jóvenes contra el racismo 
Manifestar no ser racista es sencillo, no lo es tanto cuando se lleva esta cuestión al plano de la realidad más inmediata. En primer término se interpelaba al alumno para que contestasen a la siguiente pregunta: "¿Deben tener los mismos derechos los españoles que los extranjeros?" Todos sabemos la dificultad que entraña esta pregunta; la situación económica y laboral provoca que algunos derechos sean restringidos a los extranjeros en España. De otro lado, se hacía referencia a "derechos", aludiendo no sólo a los derechos humanos, sino a todos, por lo cual resultaba más costoso afirmar su reconocimiento a los extranjeros. Los estudiantes mayoritariamente apostaron por la no diferenciación en el reconocimiento de derechos. El descenso respecto de la cuestión anterior no fue tan grande como se podía esperar. Poco más de una décima parte negó que se diera este reconocimiento, un $70 \% 10$ afirmaba sin condición alguna, condiciones que solamente plantearon algo menos de un $20 \%$ de los alumnos (ver cuadros 14 y 15). Estos últimos, en su mayoria, a la hora de oponer objeciones no estaban inspirados por sentimientos racistas, sino por móviles económicos o incluso nacionalistas, pero en pocos casos con alguna connotación xenófoba.

La pregunta 19 decía lo siguiente “Convivirias con un español de raza gitana?" Al realizar esta pregunta se pretendió indagar hasta qué punto se era coherente con las cómodas afirmaciones antixenófobas. Se puede pensar que los españoles no sabemos si somos racistas porque todavía no vivimos con tanta intensidad el fenómeno de la inmigración como otros países europeos, mas si miramos lo que tenemos más cerca, a la raza gitana, parece que la rechacemos. De nuevo sorprende el grado de aceptación étnica de los encuestados, el descenso respecto de cuestiones anteriores no es muy importante. No más de una décima parte confiesa que no podría convivir con un gitano. Aumenta el número de quienes ponen algún "pero" -una cuarta parte-; estas objeciones en algunos casos sí que encierran racismo. En todo caso, casi un $70 \%$ afirma tajantemente que conviviría sin problemas: "¿por qué no?" se aprecia de nuevo como contestación mayoritaria.

Los recién llegados a la Facultad de Derecho mostraron en mayor medida la negación del racismo; en ninguna de las preguntas alcanzan el $5 \%$ quienes lo expresan. No obstante, respecto de la convivencia con personas de raza gitana, un elevado porcentaje mostró algún tipo de condicionamiento.

Una de las preguntas de la encuesta estaba dirigida a percibir el grado de tolerancia de los encuestados; se cuestionaba lo siguiente: "¿Crees que es posible una amistad sincera entre quien se considere fascista y quien se considere comunista?" Si bien el resultado se en- 
cuentra reflejado en el cuadro, lo significativo ha sido percibir cómo se encuentra arraigada la tolerancia en el alumnado. El joven estudiante tiende a quitar importancia a lo político a la hora de establecer los sentimientos entre las personas. Independientemente del sentido afirmativo o negativo de la contestación, la intención que mayoritariamente expresó fue la de la tolerancia.

Cuadro n. ${ }^{\circ} 15$. Sentimientos xenófobos y grado de tolerancia de los encuestados

\begin{tabular}{|lrr|}
\hline Xenofobia & $\begin{array}{r}\text { TOTAL CENTROS } \\
530 \text { encuestas }\end{array}$ & $\begin{array}{r}\text { FACULTAD } \\
57 \text { encuestas }\end{array}$ \\
\hline ¿Te casarías?, p. 18 & & \\
si & $74,43 \%$ & $92,98 \%$ \\
si, pero & $21,13 \%$ & $3,51 \%$ \\
no & $4,43 \%$ & $3,51 \%$ \\
Total & $100,00 \%$ & $100,00 \%$ \\
Derechos a extranjeros, p. 7 & & \\
si & $69,78 \%$ & $87,72 \%$ \\
si, pero & $17,79 \%$ & $7,02 \%$ \\
no & $12,41 \%$ & $5,26 \%$ \\
Total & $100,00 \%$ & $100,00 \%$ \\
Convivencia con gitano, p. 19 & & \\
si & $65,96 \%$ & $7,02 \%$ \\
si, pero & $25,76 \%$ & $91,23 \%$ \\
no & $8,27 \%$ & $1,75 \%$ \\
Total & $100,00 \%$ & $100,00 \%$ \\
¿Amistad posible?, p. 20 & & \\
si & $51,97 \%$ & $45,61 \%$ \\
no & $30,53 \%$ & $43,86 \%$ \\
depende & $17,48 \%$ & $10,53 \%$ \\
Total & $100,00 \%$ & $100,00 \%$ \\
\hline
\end{tabular}

\section{OPORTUNIDAD DE UNA ENSEÑANZA DE LOS DERECHOS HUMANOS}

Desde el inicio de este estudio indicamos nuestro convencimiento de la necesidad de profundizar en una educación en derechos hu- 
manos y en el principio democrático. Para ello, aunque parezca redundante, es imprescindible una enseñanza de los derechos humanos y del principio democrático. En esta ocasión no vamos a extendernos en los motivos de esta imperiosa necesidad educativa; ya lo hemos hecho en otros trabajos. Sí ha sido este estudio un buen soporte material para argumentar este propósito. Como colofón al mismo, dos preguntas formaban parte de la encuesta realizada; estas dos cuestiones encaraban abiertamente el objetivo último de la encuesta. Si quienes la hemos trabajado creemos en la necesidad de fomentar la enseñanza de los derechos humanos, se plantea a los encuestados, destinatarios de dicha enseñanza, la oportunidad de su aplicación.

Basar la necesidad de esta enseñanza en la voluntad de los alumnos podría tacharse incluso de demagógico (sería como preguntarles si creen conveniente seguir dando matemáticas). No, no es la voluntad del alumnado la que hay que tener en cuenta a la hora de programar la enseñanza, al menos no es la única. No obstante, sí que hemos considerado interesantes sus valoraciones sobre la conveniencia de recibir una enseñanza de los derechos humanos. Por un lado, el alumnado nos ha mostrado su receptividad total a esta enseñanza; por otro lado, ellos mismos han sido quienes han exteriorizado sus carencias en este campo y, por ello, exigen esta enseñanza. Por último, la aportación de ideas para argumentar esta necesidad es enriquecedora.

El tenor de las mentadas cuestiones era el siguiente: "¿Crees que es importancia la enseñanza de los derechos humanos? ¿Por qué?»; "¿Cómo piensas que funcionaría mejor nuestra sociedad?, si los derechos humanos fueran conocidos por: especialistas / todas las personas». En este caso, los resultados no se han objetivado numéricamente. El motivo no es otro que la masiva y total contestación afirmativa del alumnado, tanto respecto de la necesidad de enseñar los derechos humanos, cuanto a la necesidad de que esta enseñanza estuviera dirigida a todas las personas, no solo a los especialistas. No llegan a la veintena el número de contestaciones en el otro sentido. La visión de esta unánime apuesta por la enseñanza de los derechos humanos, debe hacer reconsiderar la importancia que tiene en los planes de estudio.

A continuación, y en palabras de los propios estudiantes, se aprecian los motivos básicos que se arguyen en defensa de esta educación. Para empezar, existe la sensibilidad de que han de concebirse los derechos desde el punto de vista negativo, es decir, no hay que perder de vista que son deberes por cuanto su reconocimiento implica el respeto hacia los de los demás. "Yo creo que más que derechos, tenemos que pensar en deberes, porque tenemos muchos derechos pero 
ninguna obligación, somos egoístas e hipócritas». Se capta también la importancia que tiene su socialización a nivel generacional, "Sí -es importante esta enseñanza-, porque si nos los enseñan el dia de mañana iremos prevenidos y las generaciones venideras podrian hacer que sean respetados", se tiene también en cuenta que supone un factor de consolidación política. "Por supuesto, de lo contrario estaríamos volviendo a épocas pasadas".

Esta enseñanza se demanda unánimemente por la cantidad de bondades que entienden los alumnos que podría aportar a la sociedad. Bien desde el pragmatismo se afirma que "Sí -es importante esta enseñanza-, porque ya que los tenemos -los derechos humanos- ¿por qué no saber cómo emplearlos cuando los necesitamos»; subyace la idea de defensa frente a los ataques a derechos humanos, "Sí, para que todo el mundo sepa claramente cuáles son sus derechos y nunca, nunca se dejen aplastar o engañar». Se llega a considerar también a esta enseñanza casi como una panacea. "Por supuesto que lo es, es necesaria para la vida en sociedad, en comunidad, para el respeto, para la tolerancia, para la vida", "Si, porque sólo de este modo se puede transmitir a otras personas lo importante que puede ser la paz, la armonía y la tolerancia entre pueblos, de este modo se evitaría la xenofobia y el racismo, y un serio estudio de ello podria desembocar en un mundo mejor".

Ciertamente, una buena parte base su afirmación en la convicción de que con la enseñanza se actúa sobre la conciencia de las personas y, que este modo se les impulsa hacia el respeto a estos derechos: "Si porque la gente se convencería de su importancia y se cumplirían más", "Sí, porque si se enseñan desde pequeños a lo mejor esta sociedad no sería tan racista", "Si, así -enseñándolos- por lo menos lo entenderemos, nos hará pensar, no habrá tanta violación de derechos humanos, aunque -reconoce este joven- habrá gente que le entrará por un oído y les saldrá por el otron. Es evidente que el respeto de los derechos humanos no viene necesariamente por su conocimiento por las personas. Aún es más, si el respeto a los derechos estuviera causado por el hecho de la medida en que son conocidos, aún se respetarian menos, dada la actual ignorancia existente. Una de las pocas contestaciones negativas argüían que "No creo que sea tan importante -esta enseñanza-, porque todo es una cuestión de cívica, no de que te lo marquen unas leyes y lo tengas que hacer por obligación". No estaba equivocado este alumno; efectivamente, es cuestión de cívica, el problema es que no siempre se sabe hasta dónde alcanza ésta. El respeto de los derechos humanos es un buen parámetro para fijar la misma. 
Al margen de la efectividad, algunos alumnos centran el interés de su enseñanza en la propia humanidad; así destaca una afirmación tan radical como ésta: «Si -es necesaria esta enseñanza-, para aprender a vivir", asi como otras contestaciones en esta línea: "Sí, porque gracias a ello sabremos más sobre nosotros", "Si, para poder ser más personas y respetarnos los unos a los otros"; se considera que podrían hacer que nos superásemos, "pienso que se nos debería de informar más sobre lo que pasa en el mundo, sobre todo el contenido de esta encuesta, nos hace falta tener más información sobre esto para poder juzgar sobre lo que pasa en el mundo".

Hay para quienes el hecho del propio conocimiento, que sea inculcado algo tan importante, ya justifica su enseñanza: "Sí, puesto que mucha gente carece de estos conocimientos, que sin ellos es imposible vivir en sociedad, pero lo más importante no es conocerlos, es inculcarlos en la sociedad, en la mente de cada individuo", "Sí, porque cada persona ha de conocer sus derechos y los de su prójimo. Para saber tus derechos y los que has de respetar». Como desde nuestra posición sostenemos, el ser educado en los derechos humanos y el principio democrático es un derecho, forma parte del propio derecho a la educación, está ínsito en él. Algún alumno, al afirmar la conveniencia de esta enseñanza, aduce que "Sí, para que la gente tenga claro lo que es, porque yo misma claro, claro, tampoco lo tengo. Todo el mundo tiene derecho a conocer sus derechos". Por último, algunos se atreven a proyectar esta necesidad sobre el sistema educativo, afirmando que "Sí, aprenderíamos a respetar a nuestro prójimo. Pienso que debería ser algo así como una asignatura de clase para todos los cursos y en todo el mundo, Desde $1^{\circ}$ de E.G.B. hasta C.O.U.", "Sí, todo es importante y nada de esto nos enseñan, sólo cosas ya sabidas y que mañana no recordaremos. Pienso que de todas estas cosas y más nos deberían informar directamente, y no dejar que nos enteremos por personas inexpertas o que nos lo quieran vender. Porque me he dado cuenta que no tengo ni idea». No fue esta la única alusión de quienes, como este joven, se dieron cuenta de que no tenían la formación suficiente, por lo que les suponía un gran esfuerzo rellenar esta encuesta.

\section{A MODO DE RECAPITULACIÓN}

Los resultados de la referida encuesta ponen de relieve una serie de convicciones en los jóvenes que confluyen en la contradicción constante que para ellos representa la teoría y la realidad. Ello explica la 
serie de paradojas que se advierten en sus respuestas, de las que hemos destacado sólo alguna más relevante.

En sintesis, creemos poder concluir de la observación global de sus respuestas lo siguiente:

- Primero. El joven encuestado desconoce la Constitución y las Declaraciones de Derechos, así como el ideal democrático. En otras palabras, desconoce la teoría. Este desconocimiento de la teoría hace que en numerosas ocasiones valore deformemente la realidad o le lleve a diversas contradicciones o incoherencias.

- Segundo. Juzga con dureza la realidad política (o lo que de ella sabe). En muchas ocasiones afirma que sólo "en apariencia» vivimos en democracia. Cuando si cree que se vive en democracia, lo afirma sólo porque se vota y hay libertad de expresión.

- Tercero. Si algo ha calado en la educación de estos alumnos es la idea de la no discriminación, especialmente en lo que refiere al rechazo al racismo. Es éste uno de los aspectos que resulta de más agrado atender de los resultados de esta encuesta.

- Cuarto. Cree que los derechos son utopia, mientras mentalmente los vincula a la política y a la realidad que critica, pero apenas las cuestiones siguientes le van llevando al campo de lo posible de lo que él mismo sugeriría como solución, no duda en proponer la educación, la mentalización, etc.

- Quinto. Por ello, lamenta la carencia de mejor preparación en materia de derechos porque percibe que en ellos está el camino hacia una sociedad mejor $y$, por ello, se muestra partidario de su establecimiento.

- Sexto. En suma, para la formación como ciudadanos en una sociedad democrática apuestan por una educación e información en derechos, como mecanismo preventivo (respeto espontáneo de los derechos y deberes), antes que el defensivo o represivo.

Los autores se hallan convencidos de que, si les hubiera sido propuesta la lectura de la Declaración Universal de Derechos Humanos tras la realización de la encuesta, habría sido casi unánime la invocación de su art. 28: «Toda persona tiene derecho a que se establezca un orden social e internacional en el que los derechos y libertades proclamados en esta Declaración se hagan plenamente efectivos". 